\title{
Glial and Axonal Pathology in Multiple Sclerosis
}

\author{
Maria de los Angeles Robinson-Agramonte1, Alina González-Quevedo² \\ and Carlos Alberto Goncalves ${ }^{3}$ \\ IInternational Center for Neurological Restoration, \\ 2Institute of Neurology and Neurosurgery, \\ ${ }^{3}$ Federal University of Rio Grande del Sur. Porto Alegre, \\ $1,2 \mathrm{Cuba}$ \\ ${ }^{3}$ Brazil
}

\section{Introduction}

The central nervous system (CNS) consists of a series of complex structures which comprise cellular elements with basic communication functions and elaboration of information as part of their role in the process of biological adaptation and maintenance of homeostasis [Hickey WF, 2001].

\subsection{Mayor components of the CNS}

The major components of the CNS; neurons and neurites, microglias, astrocytes, ependymal cells and oligodendrocytes, establish all an important interrelationship, vital to the brain maintenance homeostasis. Ependymal cells lay around layers of astrocytes, which in turn envelop neurons, neurites and vascular elements. In addition, the normal CNS parenchyma contains blood vessels and resident macrophages. Glial cells, as they possess no conventional synaptic contacts, differ from neurons mainly establishing a rich interrelationship with other CNS components. The neuroglia, brain interstitial element, is recognized as including three groups of glial cells: 1) macroglias, such as astrocytes and oligodendrocytes,2) microglia and 3) ependymal cells.

Regarding glial function, the astrocytes are involved in glutamate uptake, repair and transport, and are part of the blood brain barrier (BBB). Studies conducted by Reese and Karnowosky [1967] indicate that the astrocyte end-feet provide little resistance to molecule movement, and that the blockage of their passage into the brain occurs at the endothelialcell-lining blood vessels. In this case, endothelial cells forming for brain vascular endothelium, play an important role in the communication between the CNS and the periphery, this latter understood as intravascular space.

Oligodendrocytes are the myelin producing cells within the CNS and are potentially highly vulnerable to immune mediated damage, since they share together with the myelin sheath many molecules with affinities to elicit specific $\mathrm{T}$ and $\mathrm{B}$ cell responses, which lead to their destruction. Oligodendrocytes do not express class I or II MHC molecules, but a wide profile of cytokine receptors, both pro-inflammatory and regulatory which have been found 
on this cell-type, suggesting their innate and adaptative ability to participate in immune response.

Microglial cells, the most interesting and enigmatic CNS type cells, play a role in phagocytosis and inflammatory response in the CNS. Under normal conditions these cells seem to be in a resting state, becoming a very active macrophage during the disease, and constituting the major effector cell in immune-mediated damage in the CNS. An explosive activity in the field of microglia cell-research conducted in the past 15 to 20 years has led to the identification of microglia as a highly efficient accessory and effector cell of the immune system. Microglia expresses class II MHC antigen upon activation [Perry \& Gordon, 1997] in the absence of a $\mathrm{T}$ cell response, which suggests that major histocompatibility complex (MHC) antigen expression may represent a marker of activation and/or a state of immunological competence. Microglia are also major producers of a large number of proinflammatory cytokines with well-known effects on T cells [Perry \& Gordon, 1997]. All the previous information supports a wide glial involvement in brain internal homeostasis maintenance that plays a major role in the regulatory function of barrier systems.

\subsection{Brain neurovascular unit}

The blood-brain barrier (BBB) system, located between the intravascular space and the brain tissue, constitutes a phenomenon of selective permeability and reduced exchange of products between the blood and the nervous system. It is a characteristic of brain capillaries and is regulated by the cells that form the neurovascular unit (NVU) [Becher et al, 2006; Nathanson \& Chun, 1990; Seyfert \& Faultish, 2003] and the dynamics of cerebrospinal fluid (CSF) flow [Becher et al, 2006; Seyfert \& Faultish, 2003]. NVU refers to the dynamic exchange among the cellular elements forming these barriers in the brain; there is a regional specialized interface between the neural tissue and the blood [Neutwelt et al, 2008].

The NVU is formed by: 1) The CSF-blood barrier, site of immunological communication between the CSF and intravascular space, which favours antigenic recognition and lymphocyte activation at this level [Bigio, 1995; Nathanson \& Chun, 1990a; Redzic et al, 2005]; 2) The meningeal barrier, that is, the aracnoid membrane, bordering the duramater, where the CSF drains to the dural venous sinuses, the olfactory nerve and the carotid sheaths[Nag S. 2003]; 3) the BBB, constituted by the brain vascular endothelium, regulates the entrance of molecules and supply of nutrients to the brain, as well as preserving the ionic homeostasis in the brain environment [Petty \& Lo, 2002]; 4) the blood-nerve barrier, which surrounds the axon tangles and includes the endothelial membrane of the endoneural capillary and the perinerium [Hemmer, 2004]; 5) the blood-retinal barrier, formed by the retinal endothelial capillary and the retinal tissue, like BBB; 6) the blood-labyrinth barrier, which has as anatomical reference the endolymph-blood and endolymph-perilymph barriers.These capillaries are lined with endothelial cells that are joined by tight junctions and physiologically form the blood-labyrinth barrier that is essential for sensitive auditory function; and 7) the blood-spinal cord barrier - with a greater permeability than the BBB which communicates with the periphery through the nerve roots plexus [Haukins \& Davis , 2005].

For centuries, the $\mathrm{BBB}$, the lack of conventional lymphatic drainage and low response to aloantigens inoculated in the CNS, were arguments to consider this compartment as a 
privileged site. Nevertheless, today it is well known, that there is no such privilege, but rather the main differences of the immune response in the brain, regarding the periphery, are in the kinetics and the degree of regulation of the different stages of the immune response at this level, which will take place under the functional control of the immune response and influence of cellular mediators acting in a regulated quantitative and temporally balanced sequence[Fisher \& Gage, 1993].

In normal conditions, neurons are unable to interact with T-cells, via MHC expression antigens, however, neurons possess unique antigenic proteins, which are normally sequestered by the BBB from the circulating immune system, making the CNS vulnerable to immune-mediated damage. On the other hand, there is increasing evidence on the ability of astrocytes to act as accessory cells of the immune system, as a facultative phagocyte able to interact with lymphocytes, since astrocytes express class II MHC antigens, essential molecules for antigen presentation to T helper cells. Astrocytes are also able to synthesize cytokines like interleukin 1, interferon $\gamma$ and tumor necrosis factor, among others. During inflammation, the mechanism of selective transport displayed by endothelial cells (EC) is disrupted and endothelial tight junctions display altered permeability with subsequent edema within and around neighboring astrocytes. Evidence of the immunological role of microglia in demyelinating diseases like Multiple Sclerosis, as well as evidences of their putative role as a major effector-cell of immune mediated cell damage at this level has been well established.

\subsection{Astrocytes as dynamic regulators of neuronal functional activity}

One of the main functions of astrocytes is the uptake of neurotransmitters released from nerve terminals. But astrocytes can also release neuroactive agents, including transmitters, eicosanoids, steroids, neuropeptides and growth factors [Anderson \& Swanson, 2000]. The regulation and mechanism (or mechanisms) of astrocyte-mediated release of neuroactive compounds are for most agents poorly defined. Release of glutamate appears to be the primary mechanism by which astrocytes modulate synaptic transmission [Kang, 1998].

In addition, astrocytes might serve neurons not so much as servants but as parents - both literally, as a developmental source of new neurons, and figuratively, as the regulators and judges of neuronal behaviour and activities. Simply stated, astrocytes command neurons what to do, besides keeping their environment clean. Interactions among astrocytes, neurons and endothelial cells define the gliovascular unit.

BBB is a diffusion barrier that regulates the exchange of molecules between the two tissues. The primary seal of the blood-brain barrier is formed by endothelial tight junctions. Astrocytes enwrap the vasculature with a large number of endfeet covering the vessel wall, although their role in BBB is poorly defined, they do not have a barrier function in the mammalian brain [del Zoppo \& Hallenbeck, 2000]. Several factors released by astrocytes might be important for the induction and maintenance of the blood-brain barrier, as manifested by the appearance of endothelial tight junctions in cells ensheathed by astrocytic endfeet. Several investigators have studied this issue and have identified agents released by astrocytes, including transforming growth factor-a (TGFa) and glial-derived neurotrophic factor (GDNF), that support the formation of tight junctions in cultured endothelial cells [Abbott, 2002]. 
In general, the interactions between the barriers conforming the neurovascular unit, constitute the base of pathological events involved in neurological diseases, with inflammatory, neurodegenerative or autoimmune components as in MS, neuromyelitis optica (NMO), posterior uveitis, CNS vasculitis, cerebral ischemia, Alzheimer's disease, among others [Brown, 2001] and at the same time they derive from transduction signals, disruption and assembling of the BBB in pathological conditions [Friese \& Fugger, 2005]. As an extension of surveys on neuroaxonal loss and inflammatory demyelination in MS, this chapter focuses on the involvement of immune factors in axonal and neuronal neurodegeneration and summarizes concepts on immune-mediated axoneuronal dysfunction and highlights the potential pathways amenable to therapeutic interventions.

This chapter will focus on the physiopathology of Multiple Sclerosis with special emphasis on glial pathology, information on viral diseases and their relationship in its physiopathology, as well as on current therapeutic aspects.

\section{Multiple Sclerosis}

\subsection{Heterogeneity in Multiple Sclerosis}

Multiple Sclerosis (MS) is a primary inflammatory demyelinating autoimmune disease affecting the CNS and the peripheral nervous system (PNS). Recent results suggest a degenerative and hemodynamic profile in this disease, which arises from the evidence of early axonal damage [Kira, 2007; Porras-Betancourt et al, 2007] and stenotic changes in the extracranial vessels that modify the NVU [Rose \& Carlson, 2007].

MS is included among the 50 neurological autoimmune diseases that affect approximately $75 \times 10^{6}$ persons in the world [Lucchinetti et al, 2000], it is more frequent in women between 20 and 40 years of age and it constitutes the major cause of neurological disability in young adults [Martinez et al, 2005; Martinez-Yélamo et al, 1998].

Neuropathology of MS shows periventricular vascular impairment and leukocyte infiltration directed toward the myelin sheath and axon [Babbe et al, 2000; Forman et al, 2006; Jiang \& Chess, 2006; Komek, 2003; Neumann et al, 2002]. Inflammation leading to progressive focal tissue damage and early axonal damage in MS could explain the current paradox concerning the temporal sequence of events that mediate axoneuronal damage in this disease, as well as the influence of immunomodulating therapy on the rate of relapses [Coles et al, 2006; Pittock et al, 2004], the persistence of oligoclonal response in the CSF and response against neurofilament proteins observed previous to demyelination. These are features that support the primary degenerating character of the disease.

MS is a prototype of neurodegenerative disease affecting primarily the axons and myelin in the CNS and the PNS. In spite of the fact that it is a disease which was described more than a century ago, the mechanism triggering the immunological reaction against myelin antigens remains unknown. Loss of myelin is accompanied by an impairment of nerve conduction leading to varied symptoms observed in this disease, that follow the formation of demyelinating plaques present in different parts of the brain and spinal cord.

It has been suggested that MS occurs as a consequence of an inflammatory response induced by the interaction of immune, environmental and genetic factors, which lead to 
demyelination, oligodendrocyte death, gliosis, axonal damage and neurodegeneration. In this sense, three aspects are of interest in the neuropathological approach of the disease: heterogeneity, viral or immune-environmental hypothesis and the axoneuronal degeneration that occurs in early stages of the disease.

MS displays a great heterogeneity that manifests itself not only in the immunogenetic pattern and the clinical forms of presentation, but also in the neuropathology, diagnosis and therapeutic response. Different authors have referred to these aspects [Bielekova et al, 2005; Lim et al, 2005] that could be defined as a) clinical neuropathological heterogeneity and b) heterogeneity related to the interpretation of neurobiological findings with respect to the diagnosis and clinical course of the disease.

\section{Heterogeneity due to the influence of genetic and immuno-environmental factors in MS}

The influence of genetic and immune-environmental factors in MS ranges from the geographic north-south distribution gradient of the disease, with a higher prevalence in developed countries, to the hygienic hypothesis [Cabre et al, 2005].

From a genetical point of view, MS displays a dominant poligenic character, with an incidence 20 to 50 times higher in first-degree relatives as compared with the general population and more than 100 genes reported. [Mirsattari et al, 2001]. Nevertheless, the highest individual genetic susceptibility is linked to MHC genes, with a distinctiveness for HLA DR $15^{*}$ aplotypes in those exhibiting a more benign course, and HLA DR4 for those with a progressive form of the disease. Also, studies in monozygotic twins show a concordance of $25 \%$ and for dizygotic twins of less than 5\%[Hillert, 2006; Lisak, 2006; Wingerchuck \& Kantarci, 2007].

Other genes reported in MS include transcription genes of MHC class II, complement system, cytokines such as IL 17 e IL 17R, IL 1R, TNFp75R, GFAP, TNF $\alpha$, TNF $\beta$, TNF $\alpha$ R, beta linfotoxin, adhesion molecules (CD11a, CD18, CD49, $\beta 7$-Integrin, transcripts for T-cells (TCR $\alpha)$, NK cells, B cells and proteases involved in antigen processing [Camerona, 2009; Gandhi , 2008]. The other hypothesis has strong supporters, due to the autoimmune character of the disease and the inflammatory and excitotoxic axonal degenerative reaction underlying the demyelinating process.

\section{Clinical heterogeneity and neuropathology in MS}

Clinical heterogeneity of MS is a consequence of the brain and spinal cord regions where plaques are located and the relapse rate - the latter is a very important element in the progression of the disease. From a clinical point of view, MS displays 4 clinical forms of presentation:1) relapsing-remitting MS, characterized by episodic exacerbations (relapses)followed by partial or complete recovery in approximately one month, and periods of clinical stability (remission); 2) primary progressive MS that displays a chronic progressive course, with no relapses; 3 ) secondary progressive MS characterized by relapses that progress in time, with less exacerbations, more incomplete recovery and irreversible disability; and 4) benign MS, which does not display a secondary progressive phase, or does not accumulate a significant disability until several decades after the onset of the disease [ Fox et al, 2006; Lee et al, 2007; McDonald et al, 2001].

In all cases, MS clinical forms overlap, along with the neuropathological patterns described for the disease [Luchinetti, 2007]. In RR-MS an inflammatory pattern prevails, while in the 
progressive form a degenerative pattern prevails.Changes in the disability scale also correspond to clinical findings and imaginological changes in MRI studies. Although other factors are involved in the heterogeneous and multiorgan character of MS, all converge with the clinical picture to characterize the disease's behavior individually.

\section{Clinical and diagnostic heterogeneity}

This aspect refers to the heterogeneity the disease management introduces in the interpretation of neurobiological variables, that allow the establishment of criteria from a prognostic point of view of the clinical course of MS, specifically for the immunological evaluation of CSF and MRI studies [Chabas, 2010; Villar, 2005].

The persistence of an oligoclonal response in the CSF of MS patients indicates the presence of a chronic inflammatory process with confirmatory value in this disease. CSF oligoclonal banding is an immunological feature not only of MS, but also of other neuroinflammatory diseases, including neuromyelitis optica.

The oligoclonal pattern that prevails in the CSF of MS patients is the presence of oligoclonal bands in CSF, but not in serum [Andersson, 1994, Correales, 2004, Falip, 2001]. It is suspected that autoantibodies can exacerbate inflammation and neurodegeneration in patients with MS, but which antigens intrathecal oligoclonal IgG recognize and how the autoimmune response is induced are still unknown [Meinl, 2008].

Heterogeneity is also associated with specific oligoclonal patterns in specific clinical forms. Thus, in the majority of cases, with primary progressive MS, a pattern of CSF and serum oligoclonal bands with additional bands in CSF is also found. On the other hand, oligoclonal bands directed to myelin lipids have been detected in RR-MS, secondarily progressive MS, but not in primary progressive MS [Camerona, 2009, Villar, 2005].

The presence of oligoclonal bands in the CSF has been considered a prognostic tool for the clinical management of these patients. Heterogeneity has also been introduced in the concordance of CSF analysis and the results of the MRI studies. According to Barkhof's criteria, different lesión patterns have been reported in patients positive or negative for CSF oligoclonal bands [Sospedra, 2009]. A lower frequency of infratentorial lesions have been reported in the MRIs of MS patients who are negative for oligoclonal bands and a higher frequency of juxtacortical lesions in patients with CSF oligoclonal bands. These associations are important in order to acquire a better comprehension and management of these patients based on the topography of the MRI lesions and their relation with the immunological response in the CSF [Sospedra \& Martin, 2009].

\subsection{Multiple Sclerosis pathology}

\subsubsection{Pathogenic mechanisms inducing Multiple Sclerosis}

The oligoclonality and specificity of autoreactive T-cells suggest that myelin protein peptides are the activating antigens predominating in MS, whose essential attributes allow them to bind the T-cell receptor related with the structure of the lateral chain of the variable region of MHC Ag. Actually, it has been stated that the degeneration of the T-cell receptor's ligand specificity is a main mechanism through which infectious agents can cause MS [Lee et al, 2007; Levin et al, 2010]. 
Among the pathogenic viruses in humans, those which induce persistent infection are relevant in MS as the triggering element of the autoimmune process that damages myelin. Herpes virus is of particular interest due to its neurotrophism, ubiquitous nature and tendency to produce latent recurrent infection. In general, there are 3 mechanisms through which viral agents can induce MS: a) molecular mimicry, b) "bystander" activation, and c) recognition of cryptic antigens [Lu et al, 2011; Levin et al, 2010].

\section{a. Molecular mimicry}

Considering the viral agents involved in the pathogenesis of MS, $83 \%$ of the patients show high titers of IgG antibodies for Epstein Barr's virus [Barnett, 2006; Wingerchuck, 2006]. The molecular mimicry hypothesis is based on the structural similarity between myelin basic protein (MBP) peptide and Epstein Barr virus peptide, followed by the activation of autoreactive T-cells for myelin and the subsequent loss of the axon's myelin [Haahr \& Hollsberg, 2006; Maghzi et al, 2010].

\section{b. Bystander activation}

Autoreactive T-cells are also activated by unspecific inflammatory events. These events can depend on the specific recognition of exposed self-antigens due to tissue damage induced by viruses, by the autoreactive immunocompetent cell's receptor or by independent recognition of viral antigens via autoreactive T/B cell's receptor. In this case, 3 mechanisms have been proposed: activation by superantigens, action of pro-inflammatory cytokines derived from viral persistence and activation by Toll- like receptors [Fujinami et al, 2006; McCoy et al, 2006].

\section{Activation by superantigens}

This mechanism involves the exposure to superantigens (superAgs), toxins derived from viral agent induced relapses. This was demonstrated in the EAE model by interaction with specific T-cell clones for MBP expressing the $\beta V$ TCR chain [Torkildsen et al, 2006].

Superantigens, are active mitogens, mostly all small basic proteins $(20-30 \mathrm{kD})$, that induce a response by binding to the MHC Ags' lateral part, which is not the usual location. Binding does not take place through the polymorphic trimolecular complex or binding Ag site, but laterally, at a specific sequence coded by genes of the $\beta V$ TCR chain. After MHC-II and TCR bind, aggregation of the receptor and cellular activation follows. Contrary to what conventionally occurs, superAgs are not processed by the antigen-presenting cells, nor are they presented in the restricted MHC self-antigens context [Fujinami et al, 2006; McCoy et al, 2006].

\section{Viral persistence and activation mediated by inflammatory cytokines}

As a consequence of persistent viral infection, virus infected antigen-presenting cells (APC), present viral peptides to $\mathrm{T} \mathrm{CD}^{+}$and $\mathrm{CD}^{+}$cells together in the context of $\mathrm{MHC}$ class antigens. The activation of these cells induces the production of INF $\gamma$ and the differentiation of T-cells via IL-12. T CD4 effector - cells secrete more INF $\gamma$ and IL-12 that stimulates the Tcells differentiation to effectors, secreting more mediators like INF $\gamma$ and TNF $\alpha$. Activated macrophages also, secrete $\mathrm{TNF} \alpha$, nitric oxide and other reactive oxygen species that damage the infected cells and other bystander non-infected cells, to be phagocytized by macrophages and dendritic cells who process and present self-antigens to T CD4 and CD8 
autoreactive cells, destroying the tissue's infected self-cells via perforins, among other mechanisms [Lassmann, 2011]. The resulting cellular detritus are captured and processed by APC and presented to autoreactive CD8-T lymphocytes who display an autoimmune reaction. In this manner, the pro-inflammatory cytokines and chemokines secreted during the infection mediate the damage, becoming activators of the T CD8 cells specific for viral antigen and autoreactive inductors of the autoimmune process [Pender: 2011]. In this case the activation and differentiation of T CD8 cells occurs in an unspecific way [Becher et al , 2007; Haahr \& Hollsberg, 2006].

On the other hand, the CNS antiviral polyspecific immune response in MS, has become a potential tool to evidence chronic autoimmune response in these patients [Cohrs, 2007]. This hypothesis has been supported by the reports showing that more than $80 \%$ of people with MS display humoral intrathecal response against neurotrophic viruses (herpes simplex, measles, rubella and varicela zoster, among others). The combined response against these neurotrophic viruses in the CNS of MS patients, was coined by Reiber et al as MRZ reaction, and many others groups have disagreed on the diagnostic value of this detection from CSF analysis in more than $90 \%$ of MS patients [Colleen et al, 2006; Correales, 2004; Jarius, 2008, Jarius et al, 2009; Luchinetti, 2007], since a similar frequency of this autoimmune chronic reaction was observed in other neurological diseases [Jarius, 2008; Jarius et al, 2009]. The MRZ reaction has also been reported in NMO patients, although in a lower frequency than in MS, and it has been useful to establish a differential diagnosis between both demyelinating diseases [Jarius, 2008]. Other MRZ reaction results were reported in tropical regions with variations regarding the previous reports [Robinson et al, 2001; Robinson et al, 2007]. In this case, a lower response to rubella virus was observed in the CNS in a smaller series of patients regarding varicela zoster and measles virus. The later showed a neurotrophic virus response similar to those reported by Reiber et al in German MS persons [Reiber et al, 1998].

We could think that a reliable interpretation of these last findings probably comes from different epidemiological factors in the two countries, or that a previous contact with this neurotrophic virus could be necessary for a detectable intrathecal polyspecific MRZ antibody response, either by immunization or native infection. In this case, as rubella is a mild disease, it may be under-reported, even in areas where reporting has been mandatory for years. As it has been previously stated [Cooper \& Alford, 2001], antibodies to rubella in people under 35 years of age is as low as 30\% in tropical countries like Trinidad or Panama, compared with more than $80 \%$ in Europe or the USA [Cooper \& Alford, 2001]; thus, the results found in Cuban patients could be comparable for our region without the influence of any additional factor.

\section{Activation by Toll- like receptors}

Although the role of innate - immunity involves native protection and maintenance of homeostasis, in some cirscumstances, it could result in a destructive autoimmunity via toll like receptor (TLR), or unspecific mechanisms due to the action of lysozime, lactoferrin, oxidative stress or the recognition of molecular structures expressed in non - infected cells with an inhibitory effect on the immune response (NK cells, complement proteins and family receptors of type C lectins, among others [Frischer; 2009]. The TLR is expressed in a wide range of immune and non-immune cells like microglias, oligodendrocytes and 
astrocytes, which act as centinels, a) by recognition of a conserved molecular pattern associated with pathogens or b) generating pro-inflammatory signals that influence the adaptative immune response [Chauhan \& Marriott, 2007].

It is believed that this mechanism initiates the lesion, previously preceded by peripheral activation. The LPS binding TLR4 increase cytokine expression and oxygen reactive species inducing peripheral autoreactive $\mathrm{T}$ cell activation and where an inappropriate TLR signal can contribute to MS development [Kielian; 2005]. In this way, the increased expresion of TLR on dendritic cells inhibit the immunosupresor effect of regulatory T cells CD4+/CD25+ on autoreactive T cells vía IL 6, causing loss of peripheral tolerance. The increase of exacerbations around viral infections in MS supports this hypothesis.

\section{Cryptic Antigens}

Cryptic or sequestered antigens are exposed as a consequence of myelin loss, induce an antibody response against them, causing reactive changes within the neuron cellular body and axon, blocking the interaction of oligodendrocyte precursors with the axon and consequently promoting remyelination and axonal repair [Devries, 2006; Magliozzi et al, 2010].

\subsubsection{Mechanism involving the axoneuronal degeneration in MS}

The investigation of neurodegeneration in MS has received the highest priority in the last few years, establishing a multifactorial process involving myelin loss, immune-mediated histotoxicity, decreased trophic support, mitochondrial damage, metabolic-energetic changes, and altered signalling [Ghafourifar, 2008; Klawiter \& Cross, 2007; Lindberg et al, 2008; Sobel, 1998].

It is commonly accepted that the initial activation of the $\mathrm{T}$ cell system takes place in the systemic immune compartment outside the CNS, where T lymphocytes encounter a specific autoantigen presented in the context of MHC class II molecules [Neumann et al, 2002] and the simultaneous delivery of additional co-stimulatory signals, such as B7-1 (CD80) and B7-2 (CD86), on the cell surface of antigen presenting cells. Such autoreactive T cells may reside quiescently at this level, until an external trigger - most likely a viral infection- renders these cells active to develop their auto aggressive potential.

The degree of neurological impairment seems to be determined by the extent of axonal loss, which is proposed to be the final step in the pathogenesis of the MS lesions. However, so far it remains unclear: (a) whether axonal injury is the result of an active destructive process targeting the axon; (b) if it occurs as a result of increased vulnerability of demyelinated axons or as part of a bystander effect; or (c) if axonal degeneration takes place as a physiological response to permanent demyelination inhibiting the extrinsic trophic signal to axons [Luchinetti. 2007].

\section{Pathogenic events involved in axoneuronal degeneration}

Two main pathogenic events must be considered as the cause of axoneuronal damage leading to irreversible discapacity in MS: a) damage of the myelin oligodendrocytic unit and b) the axoneuronal neurodegeneration process. 


\section{Damage of the myelin oligodendrocytic unit}

Indirect effect of $\mathrm{T}$ cells can also mediate damage to the myelin-oligodendrocytic unit. Autoreactive T lymphocytes activated from the periphery get into the CNS by degradation of the brain vascular endothelial cells. Th1 lymphocytes expressing adhesion molecules such as VLA-4 y LFA-1, release cytokines and metalloproteinases MMP2/9 that acting at the BBB level, induce an increase of its permeability. The later, linked with a higher integrin expression (V-CAM / I-CAM) induced by INF $\gamma$ and $\mathrm{TNF} \alpha$, facilitate the migration of activated T cells into the CNS. Once in the CNS, these activated T-cells release cytokines such as INF $\gamma$ - which induces activation and differentiation of others autoreactive $\mathrm{T}$ cells resting in the Tho state, to transform into effector cells, activating microglias, resident macrophages in the CNS and T $\gamma \delta$ cells, thus contributing to the damage. Recently it has also been postulated that $\mathrm{T}$ cell regulators can transform into Th-17 effector cells, contributing to a major lesional effect on the myelin-oligodendrocytic unit [Ishizu , 2010]. Figure 2 shows the mechanisms related with the indirect effect of $\mathrm{T}$ lymphocytes and microglia in the damage of the myelin-oligodendrocyte unit.

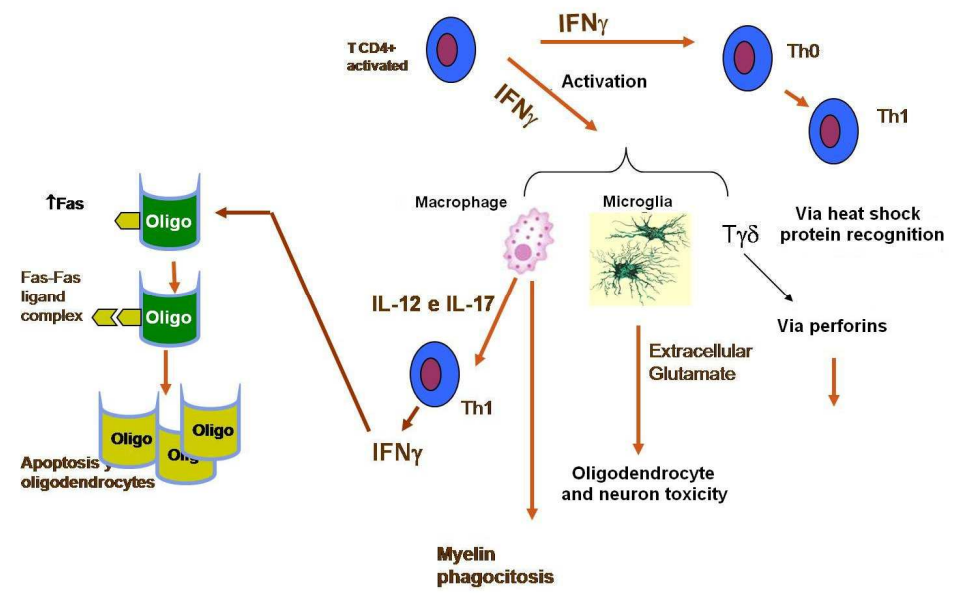

Fig. 1. Pathogenic mechanism, involving damage of the myelin oligodendrocytic unit.

Microglia interfere the oligodendrocyte repopulation and mediate their toxicity and death with the main intervention of cytokine like IFN $\gamma$ and TNFa.

Microglia also cause a toxic effect on oligodendrocytes and neurons via extracellular glutamate and nitric oxide secretion, while $\mathrm{T} \gamma \delta$ cells induce direct oligodendrocyte damage, via perforine. INF $\gamma$ - activated macrophages are also induced to secrete cytokines such as IL12 and IL 17 that induce Th1 cells to secrete more INF $\gamma$. INF $\gamma$ then induces the expression of Fas molecules on the oligodendrocyte surface promoting a Fas-Fas ligand interaction, followed by oligodendrocyte apoptotic death, Fig 1 . Thus, the microglia, main mediator of glial -neuron interaction becomes a binding point between the innate and adaptative immune systems. In acute inflammation, microglia act as antigen presenting cells (APC), and contribute to antibody clearance and elimination of myelin detritus after clinical relapse. However, during the chronic phase of a pathological condition like MS, this cell type contributes to irreversible damage. Glial-derived INF $\gamma$, also interferes with the vitality, recruitment and function of OPC, interfering with complete remyelination at lesion sites. 


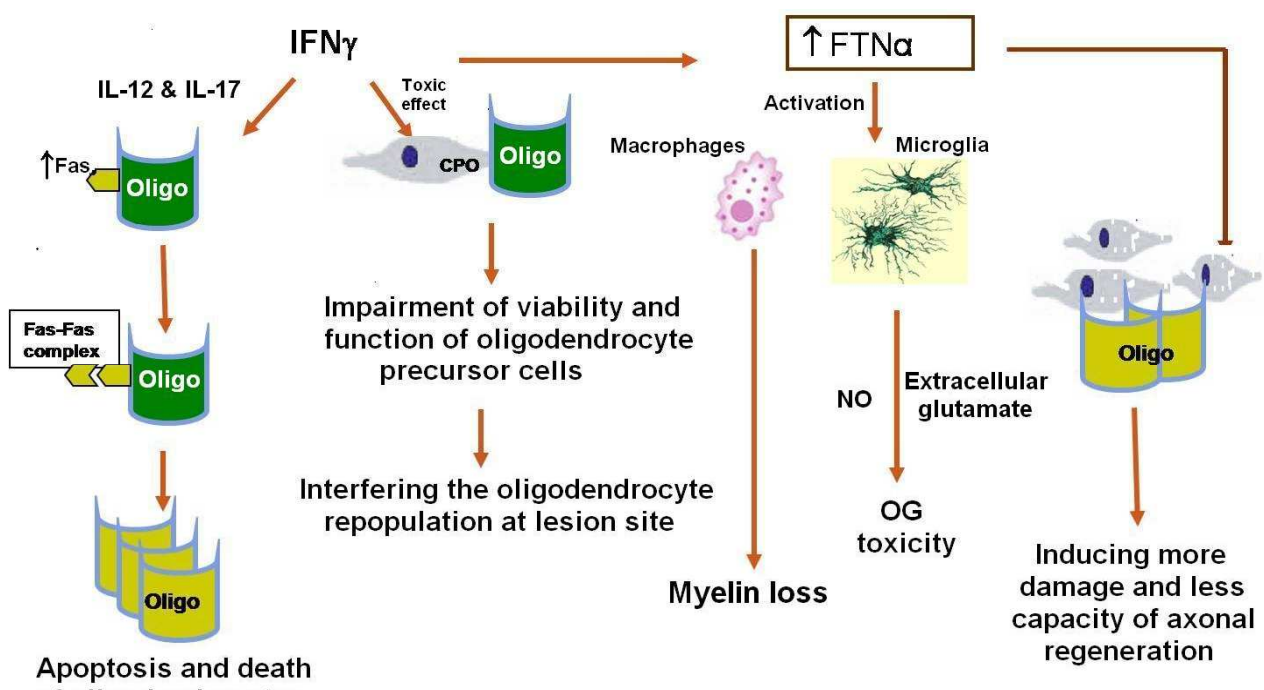

of oligodendrocytes

Fig. 2. Indirect T cell effect, on the myelin-oligodendrocytic unit in MS. Microglia also, causes a toxic effect on oligodendrocytes and neurons via extracellular glutamate and nitric oxide secretion. Th1: T-helper-1 cells.

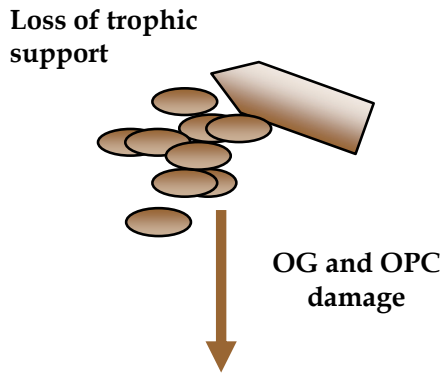

Axonal Degeneration

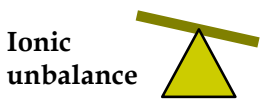

Redistribution of $\mathrm{Ca}+2$ channels at demyelinated axons and $\mathrm{Na}$ and ATP increased influx by $\mathrm{Na} / \mathrm{K}$ ATPasa bomb

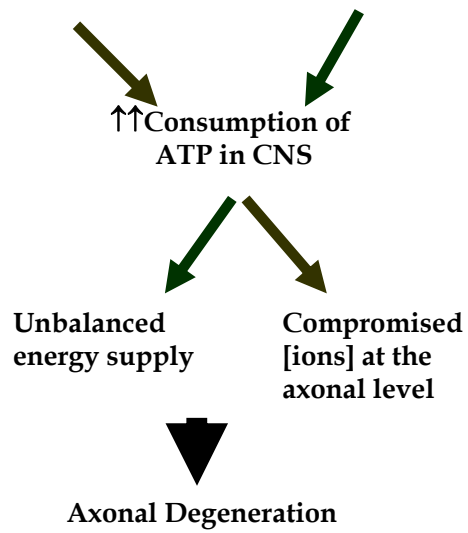

Fig. 3.Axonal damage mediated by mechanisms independent of active inflammation in MS. OG; oligodendrocyte, OPC: oligodendrocyte precursor cells. 
On the other hand, damage to the myelin-oligodendrocytic unit occurs as a consecuence of an increased vulnerability of demyelinated axons to immune attack, a reduced trophic support, since myelination provides an extrinsic trophic signal to axons. Fig 3 shows the mechanisms leading to axonal damage independent from active inflammation: loss of trophic factors and ionic and energetic unbalance, Fig 3.

Neuronal damage in MS results from two insults: on one side mediated by microglia, via IL 1beta, TNF $\alpha$, IL 6 and NO, all neurotoxic to neurons which are functionally compromised by hypoxic damage, and on the other side due to an excess of extracellular glutamate, oligodendrocyte toxicity, and axonal loss. Gene transcripts for TNF and IL 6 with an impact on the pathophysiology of MS have been identified in the margins and center of the active lesions, but not in the inactive lesions [Jack et al, 2007].

\section{Axoneuronal degeneration in MS}

Loss of trophic support in MS pathophysiology: Reduced inflammation occurring during the course of chronic demyelination suggests the existence of mechanisms not related to active inflammation as being responsible of continuous axonal loss and progressive and irreversible inability. It has been acknowledged that this is due to the loss of trophic support derived from oligodendrocyte damage, which is necessary for axonal survival independent from compact myelin (Fig 4).

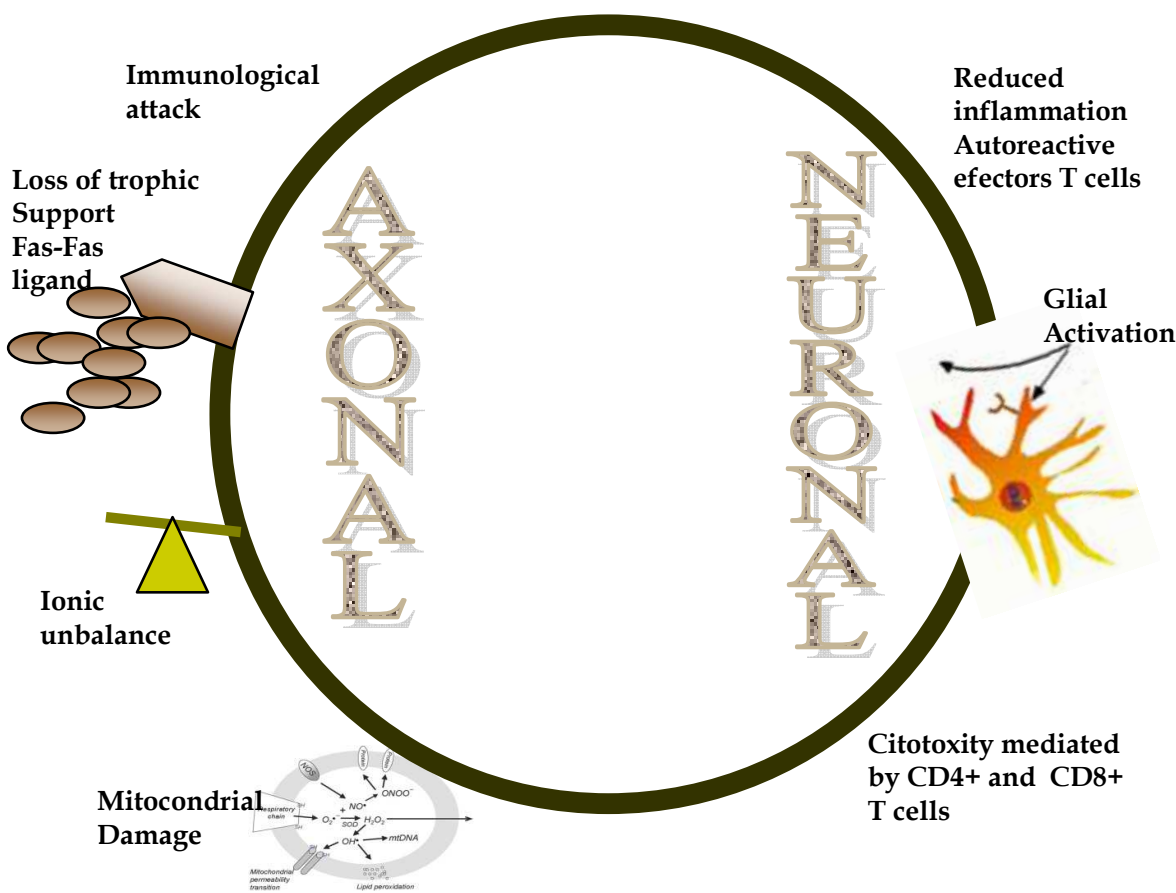

Fig. 4. Mechanism involved in the axoneuronal degeneration process. Neuroaxonal loss represents the major pathophysiological element correlating with clinical disability. The figure summarizes the mechanisms causing demyelination and axoneuronal degeneration in MS and their combined contribution to disease progression and irreversible inability. 
Ionic unbalance in MS pathophysiology: Ionic unbalance -as a result of compensatory changes to restore nervous conduction following demyelination- can induce long term axonal degeneration. Therefore, the redistribution of Na channels on demyelinated axons restores the action potential, neuronal function and increases $\mathrm{Na}$ and ATP influx, via the $\mathrm{Na} / \mathrm{K}$ ATPase pump to maintain the ionic gradient, which is necessary for neurotransmission. Both processes are highly energy consuming, leading to energetic unbalance, altered axonal ion concentrations and subsequent neurodegeneration (Fig4).

Antibodies to Cytoskeletal Proteins: Neurofilaments are a group of cytoskeletal proteins expressed in neuronal cells and axons. Neurodegenerative disorders like Alzheimer's disease and Parkinson's disease are characterized by accumulation of NF proteins leading to abnormalities in axonal transport and an impending neuronal loss [Amor et al, 2010; Arumugam et al, 2008]. Antibodies to axonal cytoskeletal proteins may be markers of axonal damage, as well as important contributors to neurodegeneration and clinical disability in MS. CSF levels of antibodies against the NFL correlate with disease duration, clinical disability, IgG index, and the degree of cerebral atrophy measured by MRI [Bartos et al, 2007; Eikelenbom, 2003]. Although elevated levels of NFL-specific antibodies are present in sera of patients with PP-MS, these antibodies are also increased in sera of patients with other neurological diseases [Bartos et al, 2007; Huizinga, 2008].

Although there is no confirmed evidence to establish that antineurofilament antibodies themselves contribute to mayor neuroaxonal damage, experimental models provide supportive evidence [Amor et al, 2010]. Immunization of mice with NFL triggers the development of a CNS disease characterized by axonal damage, paralysis, and spasticity [Huizinga et al, 2008]. Furthermore, microinjections of anti-kinesin or anti-dynein antibodies cause impairment of the anterograde and retrograde NF transport in cultured neurons [Theiss et al, 2005] and induce the formation of long and branched mitochondrial structures redistributed to the nuclear periphery. These intracellular changes are associated with altered calcium homeostasis, apoptosis, and neurodegeneration [Arumugam et al, 2009]. Antibodies to neurofilaments and possibly to other cytoskeletal proteins are produced during tissue damage in MS. Experimental data support that these antibodies may gain access to their intracellular target and cause changes in axonal transport, mitochondrial distribution and calcium homeostasis, and thus contribute to apoptosis and neurodegeneration [Vishkina \& Kalman, 2008].

Criteria based on evidence regarding the role of Ab-mediated autoreactivity to neurofilament proteins in MS has been controversial [Silber et al, 2002; Bartos et al, 2007; Bartos el al, 2007a; Bejartmar \& Trapp, 2003; Semra et al, 2002; Eikelenboom et al, 2003]. Bartos et al for example, detected increased intrathecal IgG and IgM antibodies against the medium subunit of neurofilaments (NFM) in patients with all subtypes of MS [Bartos et al, 2007; Bartos et al, 2007a] while Silber et al [2002] maintained the relevance of autoantibody to NFL in CSF as progression markers in MS. Unexpectedly, anti-NFM antibody levels appeared to be higher in the serum than in CSF, possibly related to NF antigen leakage from the CNS to the peripheral blood, or to the higher concentration of plasma cells in the blood. Alternatively, anti-NFM antibodies may be triggered by exogenous antigens and molecular mimicry in the peripheral blood [Bartos et al, 2007; Bartos et al, 2007a; Bejartmar et al, 2003; Eikelenboom et al, 2003; Semra et al, 2002; Silber et al, 2002]. 
Besides these considerations, the evaluation of axonal markers from CSF analysis, have shown different results; some experiences considering these biomarkers promissory for monitoring progression and/or relapsing rate in MS. So, a study in patients published by Eikelenboom et al, reported a significant correlation between intrathecal production of NFLP antibody in CSF and cortical atrophy and more recently a significant relationship between NFLP antibody index and relapsing rate was observed in patients bearing MS [Eikelenboom et al 2003; Robinson, 2010]. Fig 5 shows a study conducted in a group of 26 Cuban MS patients with different clinical forms of the disease. The evaluation of $\mathrm{Ab}$ reactivity to NFLP in CSF was significantly correlated with the relapsing rate, denoting an association between both clinical and biological parameters. These results are interesting since they show another aspect of the idiotipic response in MS, and its possible insertion not only from the view point of the pathogenic mechanism of the disease, but also as a useful clinical tool, at least to predict or monitor treatment response.

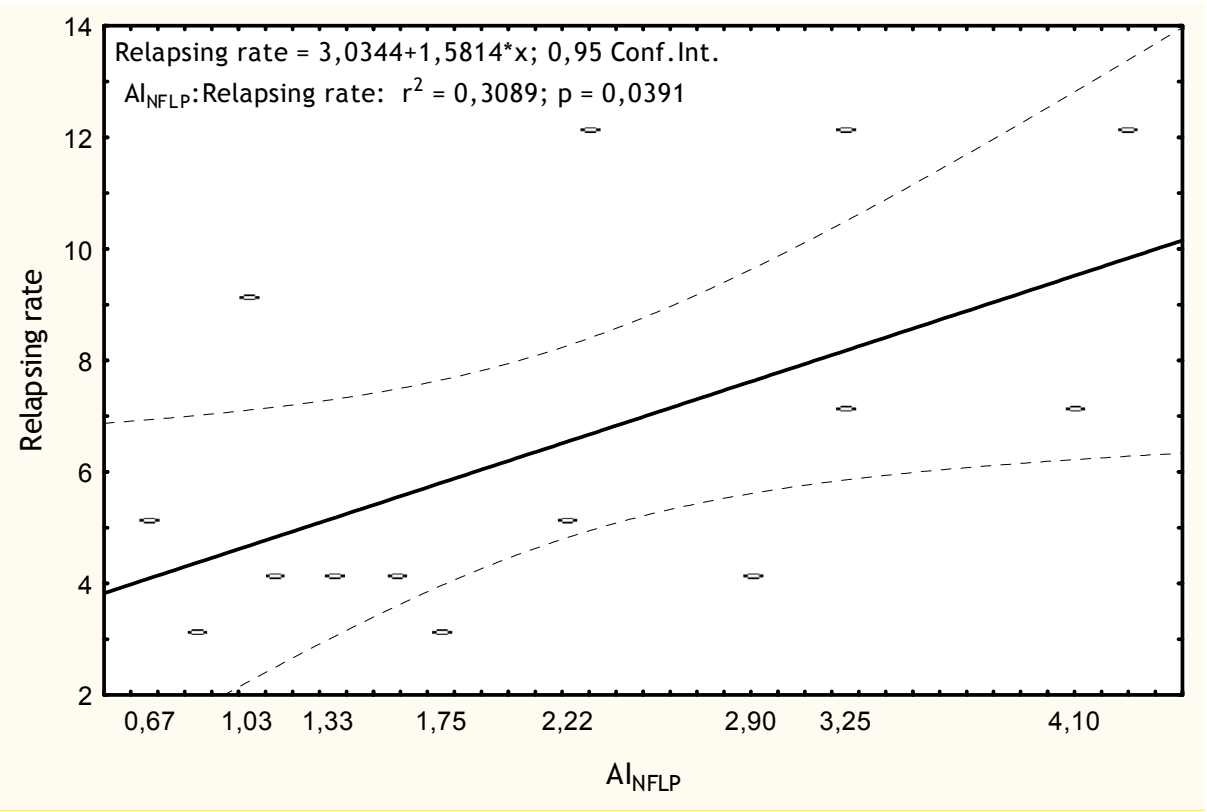

Fig. 5. Statistical analysis between $\mathrm{AI}_{\mathrm{NFLP}}$ and relapsing rate in MS patients showed a significant correlationship between both parameters. * Spearman's correlation test, $\mathrm{p}<0.05$. $\mathrm{AI}_{\mathrm{NFLP}}$ : Antibody index to neurofilament light protein. $\mathrm{AI}_{\mathrm{NFLP}}$ : NFLP CSF/NFLP Serum / IgG CSF/IgG serum.

\subsection{Autoimmunity contributing to glial pathology in MS}

Neurodegeneration in MS occurs in response to a multifactorial process involving loss of myelin protection by immune-mediated histotoxicity, decreased trophic support, mitochondrial damage, metabolic changes and altered signaling [Ghafourifar et al, 2008; Lindberg et al, 2008]. Nevertheless, different neuronal targets have been identified as causing neuronal dysfunction, following a humoral immune mechanism in MS which can be 
classified as neuronal surface molecules, intracellular enzymes, signaling molecules and chaperones, nuclear antigens and cytoskeletal protein among others (Vyshkina \& Kalman, 2008 . On the other hand, it has been suggested that microglial responses are tailored in regional and insult-specific manners [Carson et al, 2007]. The most recognizable role of microglia in brain defense is as a scavenger of cellular debris by phagocytosis, as occurs in the event of infection, inflammation, trauma, ischemia, and neuronal death [Kraft \& Harry, 2011]. However, it is well known that, not only do microglia dynamically survey the CNS to clear damaged cellular debris, but they are also capable of initiating a rapid and specific response to subtle changes in the microenvironment. Different types of neuronal pathology and other activating stimuli clearly elicit differing responses from brain-resident microglia [Colton \& Wilcock, 2010; Rivest, 2009], evidencing the autoimmune process that leads to brain damage as occurs in MS.

\section{B cells and autoimmunity in MS}

B cells are involved in multiple immune pathways including the presentation of antigenic determinants and the expression of costimulatory signals for $\mathrm{T}$ lymphocytes, immunoglobulin production, secretion of cytokines, and recruitment of T cells into the CNS. The B-cell lineage is represented by B lymphocytes (CD19p, CD138), plasma blasts (CD19p, D138p), and plasma cells (CD19_,CD138p; all detectable in CNS and CSF. In MS most of these cells express memory phenotypes, CD27p positive. A relevant contribution of humoral autoimmunity in myelin loss has been proposed in demyelinating diseases with a prominent intervention of complement molecules and Ab itself [Lucchinetti et al, 2000; Serafini et al, 2010]. Thus, immunological and molecular results have repeatedly been reported by differents groups in this field, all of them directed towards the characterization of the cellular arm of autoimmunity.

Mechanisms leading to autoimmune B-cell activation may be initiated by CD4 T helper type 2 (TH2) lymphocytes and their soluble inflammatory products (eg. interleukins 4, 5 and 13) followed by an antigen-specific expansion of clones either in the peripheral circulation or in the damaged CNS tissue, where intracellular proteins are released. As it was expressed earlier in this chapter, bystander activation describes a non-antigen-specific activation of $\mathrm{T}$ or B cells usually mediated by soluble inflammatory products of nearby immune cells, while the humoral immune system appears to be more successful in breaking anti-neuronal tolerance than the cellular system, and has greater pathogenic significance supporting the involvement of the humoral immune response in MS-related neurodegeneration [Huizinga et al, 2008].

From a molecular view point, data also support the involvement of B lymphocytes and their products in MS. Intrathecal production of immunoglobulins with an oligoclonal electrophoretic distribution pattern is a hallmark of the disease. Clonally expanded autoreactive B cells in the CSF and CNS have increased VH mutation rates concentrated in the complementarity determining regions. $\mathrm{VH}$ sequences expressed in plaques are absent in the peripheral blood [Owens et al, 2001]. B-cell heavy and light chain editing, a mechanism to prevent autoimmunity by the replacement of elements in rearranged immunoglobulin genes after the re-expression of recombination activating genes - RAG1/RAG2, is inefficient in MS, a fact which is suggested by the detection of autoreactive B cells with unsuccessfully edited receptors in the CSF [Lambracht-Washington et al, 2007; O'Connor et al, 2007] These observations suggest that CNS antigen-specific and clonally expanded B cells 
present in CNS and CSF of MS patients exhibit complex molecular characteristics and intraclonal diversity.

Neuroaxonal targets of humoral autoimmunity in MS and EAE have been identified in the CNS during the process of demyelination. Immunoglobulins produced by activated B cells in the CNS and CSF target numerous self-antigens including components of CNS myelin such as myelin basic protein, proteolipid protein, myelin-associated glycoprotein, and myelin oligodendrocyte glycoprotein [Dutta \& Trapp, 2007]. A great number of papers discuss the involvement of myelin-specific antibodies in the development of demyelination and disease progression and although not uniformly, the use of some of these antibodies as biomarkers is accepted as a support to the diagnosis or to monitor disease activity and course [Amor et al, 2007; Lutterotti et al, 2007]

\section{Anti-Neuronal Antibodies in MS}

Antibodies to a variety of intracellular molecules including enzymes, signaling molecules, HSPs, and nuclear proteins are detected in MS and other inflammatory and neurological disorders. The production of these antibodies may be related to bystander immune activation and epitope spreading during tissue injury, as was referred before, although their pathogenic significance remains uncertain in some cases.

Antibodies Targeting Neuronal Cell-Surface Molecules: Neuronal cell-surface antigen molecules in the surface membrane of myelinated axons are normally hidden from the immune system, and only become exposed after demyelination becoming antigenic and inducing the production of neuron-specific antibodies. IgG and IgM antibodies binding to the surface of a neuronal cell line were found in $70 \%$ of sera from patients with secondary progressive (SP)-MS and in $25 \%$ of sera from patients with relapsing-remitting (RR)-MS [Kraft \& Harry, 2011]. This finding may indicate the spreading of autoimmunity to neuronal antigens as a consequence of CNS expansion and tissue damage.

Axolemma-enriched fractions: Antibodies to axolemma-enriched fractions (AEF) of the CNS are also present in CSF and sera of MS patients, [Zaffaroni, 2003].From in vitro assays, there is evidences that these antibodies damage neurites and prevent neuronal outgrowth. The production of anti-axolemma and anti-myelin IgGs appears to be independent. Criteria to consider antiaxolemmal IgG antibodies as markers of axonal damage are based on these observations [Zaffaroni, 2003].

Neurofascin: One of the targets in antibody-mediated axonal injury is the cell-adhesion molecule neurofascin. The $186 \mathrm{kDa}$ neuronspecific isoform of neurofascin (NF186) is involved in the clustering of voltage gated Na channels at Ranvier's nodes, while the 155 $\mathrm{kDa}$ glial-specific isoform (NF155) is required for the proper assembly of paranodal junction, targeting the interaction sites between myelin and axon. Early in the disease course and preceding demyelination, changes in the distribution of NF155 have been observed in MS lesions [Vyshkina1 \& Kalman, 2008]. Maier et al [2007] showed that the NF155-levels were reduced, suggesting that NF155 is subject to protein degradation in the lesions. On the other hand, studies in sera showed levels significantly higher in patients with chronic progressive forms of MS compared to other inflammatory neurological diseases. At the same time, studies in vitro showed that antibodies to neurofascin inhibit axonal conduction and that NF155-specific antibodies cross-react with NF186-transfected cells at the nodes of Ranvier 
possibly initiating axonal injury and accelerating disease progression [Mathey et al, 2007]. Neurofascin-specific antibodies can also inhibit remyelination by binding to NF155 expressed on the surface of oligodendrocytes. In vivo experiments revealed that antibodies to neurofascin and complement can selectively target nodes of Ranvier, cause axonal injury, and trigger disease exacerbation in EAE [Mathey et al, 2007].

Anti ganglioside antibodies: It is well known that gangliosides are glycolipids with sialic residues in the outer layer of cell membranes, particularly enriched in the membranes of neurons. Experimental data reveal that antiganglioside antibodies can disrupt the BBB, create neuromuscular block by binding to neuronal gangliosides at the neuromuscular junction and inhibit axonal regeneration after peripheral nerve injury in mice [Amor et al, 2010],. Increased levels of anti-GM3 (monosialoganglioside) antibodies can be found in sera of a great proportion of patients with progressive forms of MS (56.3\%) in primary progressive (PP)-MS and in $42.9 \%$ of SP-MS vs $2.9 \%$ in RR-MS and $14.6 \%$ in OND. Anti-GD2 (disialo-ganglioside)-like IgM autoantibodies were detected in sera of $30 \%$ of MS patients, and a positive correlation of anti-GD2-like IgM reactivity with neurological disability was observed [Kanda et al, 2000]. The increased prevalence of GD2-specific IgM antibodies in SPMS (47.8\%) compared to RR-MS (24.2\%) and PP-MS (26.7\%), also suggests the involvement of these antibodies in inflammation-induced neurodegeneration [Marconi et al, 2006]. It should be emphasized; that it is not clear whether anti-ganglioside antibodies can cause or result from axonal damage, and whether they may definitely function as putative markers of neurodegeneration in MS.

In general, these data suggest that antibodies specific to neuronal cell-surface molecules are produced during demyelination, and that they may themselves contribute to glial pathology or axonal injury in MS. These antibodies can activate complement and exert cytotoxicity, provide binding sites for the Fc receptors on macrophages and microglial cells, interrupt axon-myelin interaction, inhibit axonal conduction and outgrowth, disrupt the BBB, and alter oligodendrocyte functioning. Correlation of the antibody titers with the severity of disability offers an opportunity of using these neuronal cell-surface antibodies as biomarkers.

\section{Antibodies to Intracellular Molecules: Arrestins, glutamate decarboxylase and nuclear antigens}

MS patients show a high prevalence of autoreactivity to intracellular antigens such as neuron-specific enolase (metabolic enzyme), b-arrestin and retinal arrestin among others. So, antibody reaction to arrestins, a family of multifunctional, intracellular proteins that regulate signal transduction and the activity of G-protein-coupled receptors, has been reported in MS; while b-arrestin- 1 enhances the expression of antiapoptotic $\mathrm{Bcl} 2$ that may control the development of both MS and EAE. Anti-b-arrestin-specific antibodies and antibodies to retinal arrestin can be found in sera of patients with MS. [Gorczyca et al, 2004]. B-Arrestin-1-knockout mice are more resistant, and b-arrestin-1 transgenic mice are more susceptible to EAE [Frederick \& Miller, 2007; Shi et al, 2007].

Immunity to glutamate decarboxylase (GAD), an enzyme that converts glutamate into the inhibitory neurotransmitter aminobutyric acid (GABA), can also be detected in MS. GAD is expressed in various cell types including neurons, and its activity is reduced in sera of MS patients. Serum anti- GAD65 antibodies are present in 10\% of MS patients [Hermitte et al, 
2000]. Anti-GAD antibodies have also been associated with systemic autoimmune disorders, such as type 1 diabetes, although without a clear understanding of the pathogenic significance [Taplin \& Barker, 2008]. Elevated antinuclear antibodies (ANA) in sera of MS patients have been reported at varying frequencies $(2.5-81 \%)$ depending on the methodological approaches [Ferreira et al, 2005; Roussel et al, 2000]. In contrast, the ANA titers are low (between 1:40 and 1:100) in sera of MS patients, who also often have lowaffinity IgG antibodies to multiple other nuclear and cytoplasmic epitopes. [ Ferreira et al, 2005; Roussel et al, 2000; Lu \& Kalman, 1999]. These data suggest that detection of ANA and related antibodies in MS may result from a nonspecific immune activation.

Furthermore, these observations support that B cells may contribute directly or indirectly to MS development. Removal of immunoglobulins from the peripheral blood by plasmapheresis appears to be beneficial in the subgroup of patients with type II lesions [Keegan et al, 2005] and depletion of CD20 B cells by rituximab results in a significant reduction in the number of enhancing MRI lesions. The latter intervention, however,does not exert its beneficial effects by directly affecting the immunoglobulin pool, but by depleting memory $\mathrm{B}$ cells and altering antigen presentation, T-cell activation, or T-cell recruitment into the CNS [Hauser et al, 2008].

\section{Autoimmunity and Glutamate-Mediated Neurotoxicity}

Glutamate is a neurotransmitter released by neurons into the synaptic space where it binds to its postsynaptic receptors. Elevated levels of extracellular glutamate can lead to the death of neurons, astrocytes and oligodendrocytes [Matute et al, 2006]. Excitotoxic tissue damage mediated by glutamate has been described in a number of neurologic diseases (eg stroke, traumatic injury, neurodegeneration) including MS [Vercellino et al, 2007].

Glial cells and neurons express various types of glutamate excitatory amino-acid transporters (EAAT1-EAAT5). The reuptake of glutamate appears to be impaired in MS due to the downregulation of EAAT1 and EAAT2 molecules in white matter and cortical lesions[Vercellino et al, 2007]. Glutamate levels in the CSF are higher during relapses than remissions, and correlate with disease severity [Sarchielli et al, 2003.) These observations suggest that inflammation upsets the balance of glutamate release and re-uptake, and the excessive glutamate may escalate tissue injury in MS.

Glutamate toxicity may be further enhanced by altered receptor expression and signaling.Two main subtypes of glutamate receptors have been identified: ionotropic, coupled directly to membrane ion channels; and metabotropic, coupled to G proteins. The ionotropic receptors are divided into three subtypes based on their selective agonists: Nmethyl-D-aspartate (NMDA), a-amino-3-hydroxy-5-methyl-4-isoxazolepropionate (AMPA), and kainate [Lipton \& Rosenberg, 1994]. An elevated expression of subunit 1 of AMPA receptor (GluR1) on oligodendrocytes at the borders of active plaques, and subunit 3 of AMPA receptor (GluR3) and metabotropic glutamate receptors (mGluR) on reactive astrocytes in MS lesions have also been reported. Activated microglia and macrophages are immunopositive for NMDA receptor subunit 1 (NR1) in plaques and may also play a role in Ca-dependent injury of oligodendrocytes and neurons. NMDA receptor antagonists, memantine, amantadine, and MK- 801 reduce neurological deficits in EAE, and the blockade of AMPA receptors by antagonists, also ameliorate clinical signs of EAE. [Bolton \& Paul, 1997; Smith et al, 2000; Stys \& Lipton, 2007; Wallstrom 1996]. 
Antibodies targeting glutamate receptors may have agonist or antagonist effects. Agonists usually cause excitotoxicity and complement-mediated cell death [Groom et al, 2003]. AntiGluR3 antibodies are implicated in epilepsy syndromes but not in MS. In summary, these observations suggest that glutamate homeostasis is being upset in inflammatory lesions of MS, where the concentration of glutamate is increased, at least in part, due to a decreased reuptake. In addition, anti-glutamate receptor antibodies are associated with inflammatory and neurodegenerative disorders, like MS, often correlating with clinical improvement.

\section{Induction of Central Nervous System Autoimmunity by Th17 lymphocyte in MS}

T-helper cells classically divide into two functional subsets including: Th1 and T-helper-2 (Th2); each one with a distinct activity of transcription factor and pattern of cytokinesecretion phenotype [Mosmann et al, 1986.]. Th1 cells produce IFN- $\gamma$, TNF- $\beta$ and interleukin-10 (IL-10), and mediate cellular immune responses against tumor cells, intracellular viruses and bacteria via macrophages and cytotoxic T-cell activation. In addition, Th1 cells drive cell-mediated response leading to tissue damage and drive humoral immune responses to Ig2a subclasses. Innate immune cells, through STAT6 signals, secrete IL-4 that induces the transformation of nave CD4+ T cells into Th2 cells, leading to the expression of transcription factor GATA3. This cascade of events in turn results in the production of IL-4, IL-5, IL-13, IL-21 and IL-31, important for host defense against helminths and contribute to the pathogenesis of asthma and allergy [Monteleone et al, 2008; Steinman, 2007; Wilson et al, 2009]. Other T-cell subsets that co-express CD4 and CD25 are Th3 cells, or regulatory $\mathrm{T}$ (TREG) cells, which regulate both Th1 and Th2 cell function, and maintain homeostasis of the immune system [Vojdani \& Lambert, 2011]. TREG cells can develop from thymic CD4+ T-cell precursors in the presence of IL-2 and TGF- $\beta$, which are termed natural TREG cells. TREG cells produce low levels of IL-2 and IFN- $\gamma$, but produce high levels of IL10 , IL-35 and TGF- $\beta$, suppressing immune responses to self-antigens and preventing autoimmune disease by two different immunoregulatory immunosuppressive or antiinflammatory cytokines, IL-10 and TGF- $\beta$, Fig 6.

More recently, a specific T-cell subset, termed Th17 cell, that secretes a cytokine called IL-17, has been identified. This cell develops from nave CD4+ T cells in response to IL-6, IL-23, TGF- $\beta$ and IL- $1 \beta$. IL- 6 and IL-23 activate STAT3, which increases the expression of ROR $\gamma$ t and ROR $\gamma$ transcription factors, promoting the expression of IL-17A, IL-17F, IL-21 and IL-22. These cells, important for host defense against extracellular bacteria, are also involved in mediating autoimmune diseases [Chung \& Dong, 2009; Stockinger \& Veldhoen, 2007]. The immunopathogenic activities of Th17 cell in inflammation and autoimmunity has been linked to a growing list of cancers, autoimmune and inflammatory diseases such as rheumatoid arthritis, systemic lupus erythematosus, multiple sclerosis, asthma, psoriasis, systemic sclerosis, chronic inflammatory bowel disease and allograft rejection [Chung \& Dong, 2009; McGeachy et al, 2009; Steinman, 2007].

Th1 and Th2 effector molecules antagonize the development of Th17 cells, which are responsible for destructive tissue pathology in autoimmune diseases including neuroinflammation; whereas, nave CD4 cells in the presence of IL-12 and transcription factors, such as T-bet and STAT4, become Th1 cells, which express IL-12R and produce IFN$\gamma$. Nave CD4 cells in the presence of IL-4, GATA-3 and STAT6 become Th2 cells, which produce IL-4. Finally, naive CD4 cells in the presence of TGF- $\beta$, IL-23 and transcription factor ROR $\gamma$ t become IL-17-producing Th17 cells [Batten et al, 2006; Cheung et al, 2008]. 
As it was previously mentioned, the pathogenic contribution of Th1, Th2 and Th17 lymphocytes to autoimmune disorders has been reported both in systemic and in neurological diseases [Zheng et al; 2007]. IL-17-producing T-helper cells play an important role in the induction of neuroimmune diseases, like MS and its animal model called experimental autoimmune encephalomyelitis (EAE) [Iwakura \& Ishigame, 2006.]. This observation is based on the detection of IL-17 levels in both the plaques and cerebrospinal fluid of MS patients [Ishizu et al, 2005].

It has been established that IL-17 is a proinflammatory cytokine that stimulates epithelial, fibroblast and endothelial cells to produce other inflammatory chemokines and cytokines, including macrophage inflammatory protein (MIP)-2, monocyte chemoattractant protein (MCP-1), granulocyte-colony stimulating factor (G-CSF) and IL-6 and synergizes with IL-1 $\beta$ and TNF- $a$, to induce more chemokine expression [Vojdani \& Lambert, 2011].

Also, microglia is known either as antigen presenting cells and effector cells and is involved in inflammatory demyelination of the CNS. It was shown that treatment of microglia with IL-17 upregulated microglia production of IL-6, MIP-2, nitric oxide, neurotrophic factors and adhesion molecules. In a similar way IL-1 $\beta$ and IL-23 may induce microglial IL-17 production, contributing to neuroimmune pathology in MS [Kawanokuchi et al, 2008]. An additional support to this hypothesis came from the experience in mice injected with specific antibodies against IL-17, which resulted in inhibition of chemokine expression, whereas overexpression of IL-17 in lung epithelia resulted in chemokine production and leukocyte infiltration [Vojdani \& Lambert, 2011].

In MS, the location and distribution of CNS lesions under the influence of genetic susceptibility is determinant for clinical outcome and disease course and suggests that T-cell immune response specificity influences the sites of inflammation. A recent study published by Stromnes et al in 2008, demonstrated that T-cells specific to MBP epitopes generate two different populations of helper cells, Th17 and Th1 [Stromnes et al, 2008]. Notably, the Th17 to Th1 ratio of infiltrating T-cells determines that inflammation in the brain parenchyma occurs when the ratio of Th17 to Th1 cells is much greater than one, triggering a disproportionate increase of IL-17 in the brain that results in inflammation, Fig.6. At the same time, these results indicate that Th17, Th1 and their ratio, are main mechanisms regulating cell infiltration into the brain parenchyma.

Stromnes' group also considered that a differential regulation of inflammation in the brain with a Th17:Th1 ratio >1, and in the spinal cord with a Th17: Th1 ratio <1, indicates that Th1 cells play a significant pathologic role in spinal cord autoimmunity [Stromnes et al, 2008]. It was concluded that IL-17 produced by Th17 cells is the major regulator of CNS autoimmunity. So, IL-17, deemed as the most pathogenic cytokine in inflammatory neuroimmune and autoimmune disorders, induces the activation of matrix metalloproteinase-3 (MMP-3) and recruits neutrophils to the site of inflammation, which also activates MMPs, proteases and gelatinases, contributing to BBB breakdown and a further enhancement of neutrophil recruitment. This increase in protease activity, which attracts a significant number of monocytes and macrophages to the inflammatory sites, with a subsequent citokine secretion and glial activation, reinforces the eventual myelin and axonal damage [Tester et al, 2007]. Thus, it is possible to consider that under CNS inflammatory conditions, microglia, which act as antigen presenting cells, produce IL- $1 \beta$ 
and IL-23 and act in an autocrine manner, via IL-17 expression in microglia and IL-17induced activation of MMP-3, contributing to neuroimmune pathology in MS.

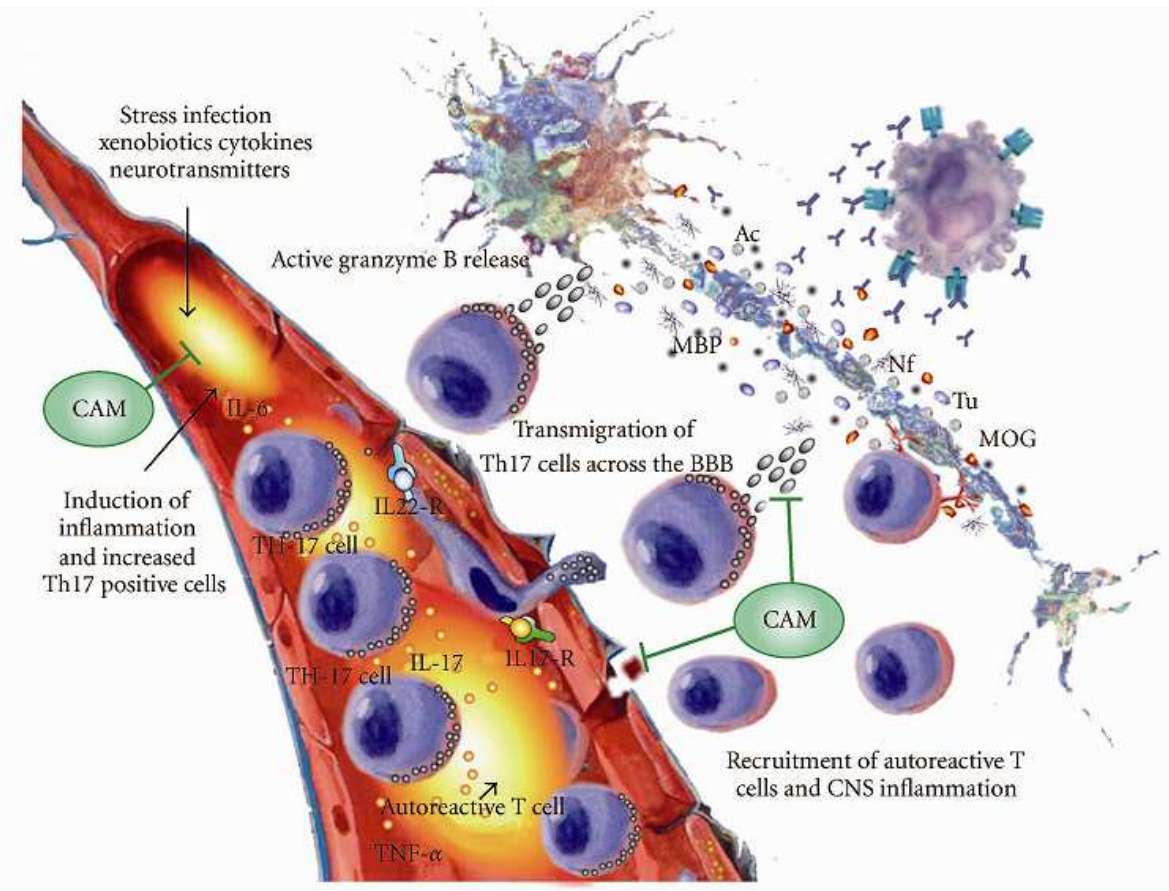

Fig. 6. The role of Th17 lymphocytes in the pathogenesis of inflammatory and neuroimmunological disorders. Environmental factors' induction of inflammatory response, production of cytokines and increase in the number of Th17 positive cells in circulation. Expression of IL-17 and IL-22 receptors on blood-brain barrier endothelial cells result in the binding of Th17 cells to BBB tight junctions. This disrupts the tight junctions, and the Th17 cells then transmigrate across the BBB, setting the stage for the killing of neurons by the release of granzyme B. CAM protocols may be used to block the inflammatory cascade induced by infection. CAM: Complementary alternative medicine, BBB; blood brain barrier. Taken from: The Role of Th17 in Neuroimmune Disorders: Target for CAM Therapy. Part II. In Hindawi Publishing Corporation Evidence-Based Complementary and Alternative Medicine, Volume 1-7, 2011.

\section{Induction of BBB Disruption and Neuroinflammation mediated by IL 17 in MS}

The BBB is composed of two layers: the microvascular endothelial cells and the glia limitans formed by glial foot processes [Maes et al 2007]. The perivascular space between the endothelial cells and astrocytes is populated by macrophages, which behave like immature dendritic cells [Vojdani \& Lambert, 2011]; thus factors able to open the epithelial barrier will destroy both the BBB and neural tissue [Maes et al 2007; Maes et al, 2008].

Since microglia play a significant role in MS, to further strengthen the role of IL-17 in CNS inflammation, microglia were treated with IL-17. Treatment with IL-17 upregulated the 
microglial production of IL-6, MIP-2, nitric oxide, adhesion molecules and neurotrophic factors [Kawanokuchi et al, 2008]. Since it is known that IL-17 can be secreted by microglia in response to IL-1 $\beta$ or IL-23, these results strongly suggest that the cells co-expressing IL-17, IL-22 and granzyme B through the action of IL-17 and IL-22, play a significant role in the induction and breach in the BBB and its permeabilization to circulating CD4+ lymphocytes and soluble molecules resulting in CNS inflammation [Vojdani \& Lambert, 2011]. The role of Th17 lymphocytes in the pathogenesis of inflammatory and neuroimmunological disorders is shown in Figure 6 . This role of Th17 cells and the IL-17 produced by them in neuroinflammation could make these novel CD4 cells a suitable target for treatment in demyelinating diseases like MS.

Therapies towards BBB repair and the inhibition of lymphocyte transmigration can reduce neuro-inflammation, and at the same time, could be relevant since resident microglia and astrocytes, play an important role in the initiation and progression of immune responses induced by pathogen invasion or their antigens [Chauhan and Marriott ; 2007]. So, infections associated with high levels of inflammatory cytokines including IL-1 $\beta$, IL-6, TNF- $a$ and IL-17 in the CNS may result in neurological dysfunction. In this case, microglia and astrocytes via TLR and nucleotide-binding domain promote the recruitment and antigen-specific activation of infiltrating leukocytes [Rock et al.; 2004; Kielian; 2005].

Accumulated evidence has shown that substance P (SP), the most abundant tachykinin in the brain, also plays an important role in the inflammatory immune responses at peripheral sites [Vojdani \& Lambert, 2011]. Neuropeptide SP, with its high affinity receptor NK-1R is expressed on microglia and can also modulate the function of myeloid cells, such as dendritic cells and macrophages via a high affinity receptor called neurokinin-1 (NK-1). SP with NK-1R activate the transcription factor NF- $\kappa \mathrm{B}$, which facilitates the production of key proinflammatory cytokines such as TNF- $a$, IL- 6 and IL-17, and also reduce the production of immunoregulatory cytokines (TGF- $\beta$, IL-10) by macrophages; thereby further exacerbating inflammation [Vojdani \& Lambert, 2011]. The mechanism of bacterial antigens inducing the neuronal SP production and it's binding to SP receptors, result in cytokine production and brain inflammation. Furthermore, products, such as SP receptor antagonists for the inhibition of NF- $\kappa \mathrm{B}$, or minocycline, $a$-Lipoic acid, resveratrol [Aebischer \& Kato; 2007; Lampl et al, 2007] or quercetin [Sternberg et al, 2008], which are known to be effective in the repair of BBB damaged by infections, may represent important new therapeutic strategies to combat potentially disabling consequences of inflammation within the brain.

\subsection{Current perspective on treatment in MS}

Further evidence to support the importance of neurodegeneration in MS is obtained from clinical data showing only a partial success of the available disease-modifying drugs (interferons, Glatiramer Acetate, monoclonal antibodies to antigenic determinants expressed on T lymphocytes, among others), which impede activation and migration of inflammatory cells via the $\mathrm{BBB}$, but have no direct effect on the degenerative processes in the CNS. [Antel \& Miron, 2008; Bergamaschi et al, 2006; De Jager , 2007; Miron et al, 2008; WeinstockGuttman, 2006].

The research community has clarified the underlying biology of MS and shown great promises for developing an improved therapy. Areas of research that hold promise in the 
near future include: 1) the development of drugs that block the movement of myelinattacking $\mathrm{T}$ cells from the bloodstream into the brain, 2) engineering drugs that specifically inhibit the damaging $\mathrm{T}$ cells or antibodies, 3) finding approaches that promote remyelination (myelin ro treatment in MS repair), which may allow individuals to regain function and 4) studies of MRI, immune, and genetic variables that improve our ability to predict the disease course, and tailor or engineer therapy to individuals with MS.

Trials of stem cell transplantation, with the goal of repopulating oligodendrocytes, are underway in people with MS. Remyelination may also be promoted by blocking leucine rich repeat and Ig domain-containing, Nogo Receptor-interacting protein 1 (LINGO-1), a protein on the surface of neurons that inhibits differentiation of precursor oligodendrocytes into mature cells. Antibody blockade of LINGO-1 has shown promise in an animal model of MS [Loeb, 2007]. Neurotrophins are protein factors produced by CNS cells that support neuronal growth, survival and differentiation [Azoulayet al, 2008]. In MS, secretion of the neurotrophin brain-derived neurotrophic factor is low and dysregulated [Mi et al, 2009] and BDNF is therefore also being considered as a therapeutic target. Current MS therapeutics are moderately effective for modifying disease during its relapsing-remitting phase. There are a number of oral and parenteral agents that target developing inflammation, and several are likely to be approved for treatment of RRMS within the next few years. These therapies will likely more effectively control RRMS but will also carry greater known and, as yet, unknown safety risks. These risks and benefits will have to be weighed carefully against the efficacy and proven safety of the IFNs and Glatiramer acetate. Furthermore, none of the anti-inflammatory therapies currently in late stage of development are likely to benefit patients with SPMS and PPMS. Development of effective neuroprotective and neurorestorative therapies are needed in order to benefit patients with progressive MS.

\section{Conclusion}

Since MS shows a great heterogeneity, the influence of multiple etiopathogenic factors could be considered as the main cause of this behavioral pattern. Nevertheless the well established hypothesis on the aetiology and pathogenic mechanisms described for this disease are not enough, at least to explain the wide clinical variations in response to treatment. From this view point, it is true that serious contributions have been achieved, but more protocols must be conducted for a major understanding of MS pathology, as well as for a more effective response to treatment.

\section{References}

Abbott NJ 2002 .Astrocyte-endothelial interactions and blood-brain barrier permeability. J. Anat. 2009, 629-638.

Aebischer P and. Kato A C. 2007. Playing defense against Lou Gehrig's disease. Scientific American, 297: 86- 93.

Amor S, Giovannoni G. 2007 Antibodies to myelin oligodendrocyte glycoprotein as a biomarker in multiple sclerosis - are we there yet? Mult Scler, 13:1083-1085.

Amor S, Puentes F, Baker D \& van der Valk P. 2010. Inflammation in neurodegenerative diseases. Immunology, 129: 154-169.

Anderson, C.M. and Swanson, R.A. 2000 Astrocyte glutamate transport: review of properties, regulation, and physiological functions. Glia 32: 1-14. 
Anderson, M, Alvarez-Cermeño, J, Bernardi, G \& Cogato, I. 1994. Cerebro Spinal fluid in the diagnosis of multiple sclerosis: a consensus report. J Neurol Neurosurg Psych, 57: 897-902.

Antel JP \& Miron VE. 2008. Central nervous system effects of current and emerging multiple sclerosis-directed immuno-therapies. Clinical Neurology and Neurosurgery 110: 951-957.

Arumugam TV, Woodruff TM, Lathia JD, Selvaraj PK, Mattson MP, Taylor SM. 2009 Neuroprotection in stroke by complement inhibition and immunoglobulin therapy. Neuroscience.

Azoulay D, Urshansky N, Karni A. 2008Low and dysregulated BDNF secretion from immune cells of MS patients is related to reduced neuroprotection. J Neuroimmunol, 195:186-193.

Babbe, H, Roers, A \& Waisman, A. 2000. Clonal expansion CD8+ T cells dominate the T cell infiltrate in active multiple sclerosis lesions as shown by micromanipulation and single cell polymerasa chain reaction. J Exp Med, 192: 393-404.

Barnett M.H. \&, Sutton I. 2006. The pathology of multiple sclerosis: a paradigm shift. Curr Opin Neurol , 19: 242-47.

Bartos A, Fialova L, Soukupova J, Kukal J, Malbohan I \& Pitha J. 2007 Antibodies against light neurofilaments in multiple sclerosis patients. Acta Neurol Scand,116: 100-7.

Bartos A, Fialova L, SoukupovÃ $i$ J, Kukal J, Malbohan I \& Pitha J. 2007a. Elevated intrathecal antibodies against the medium neurofilament subunit in multiple sclerosis. J Neurol, 254: 20-25.

Batten M., Li J., Yi S et al. 2006. Interleukin 27 limits autoimmune encephalomyelitis by suppressing the development of interleukin 17-producing $\mathrm{T}$ cells. Nature Immunology, 7: 929-936.

Becher B, Bechmann, I \& Greter, M. 2006. Antigen presentation in autoimmunity and CNS inflammation: how T lymphocytes recognize the brain. J Mol Med; 84: 532-43.

Bejartmar C, Trapp B.D. 2003. Axonal degeneration and progressive neurologic disability in multiple sclerosis. Neurotox Res , 5: 157-64.

Bergamaschi R, Kappos L, Antel J, Comi G, Montalban X, O'Connor P, et al. 2006. Oral Fingolimod (FTY720) for Relapsing Multiple Sclerosis. N Engl J Med; 355: 1124-40.

Bielekova, B, Kadom, M \& Fisher, E. 2005 MRI as a marker for disease heterogeneity in Multiple sclerosis. Neurology, 65: 1071-76.

Bigio, MR. 1995. The ependyma. A protective barrier between brain and cerebrospinal fluid. Glia; 14:1-13.

Bolton C, Paul C. MK-801 limits neurovascular dysfunction during experimental allergic encephalomyelitis. J Pharmacol Exp Ther 1997; 282: 397-402.

Brown K.A. 2001. Factors modifying the migration of lymphocytes across the blood-brain barrier. Int Immunopharmacol, 1: 2043-62.

Cabre P, Signate,A, Olindo, S; Merle,H ; Caparros-Lefebvre, D, et al. 2005. Role of return migration in the emergence of multiple sclerosis in the French West Indies. Brain, 128: 2899-2910.

Camerona EM; Spencera S; Lazarinia, J; Harpa, CT; Wardb,ES; et al.2009. Potential of a unique antibody gene signature to predict conversion to clinically definite Multiple Sclerosis. J Neuroimmunol, 213: 123-130. 
Carson, M.J.; Bilousova, T.V.; Puntambekar, S.S.; Melchior, B.; Doose, J.M.; Ethell, I.M. 2007. A rose by any othername? The potential consequences of microglial heterogeneity during CNS health and disease. Neurotherapeutics, 4: 571-579

Chabas, D; Ness, J; Belman, A; Yeh, EA; Kuntz, N; Gorman, MP; et al. 2010. Younger children with MS have a distinct CSF inflammatory profile at disease onset. Neurology, 74: 399-405.

Chauhan V S \& Marriott I. 2007. Bacterial infections of the central nervous system: a critical role for resident glial cells in the initiation and progression of inflammation. Curr Immunol Rev, 3: 133-143.

Cheung P.F.Y., Wong C.K., and Lam C.W.K. 2008. Molecular mechanisms of cytokine and chemokine release from eosinophils activated by IL-17a, IL-17f and IL-23: implication for Th17 lymphocyte-mediated allergic inflammation. J Immunol 180: 5625-35.

Chung Y. \& Dong C. 2009. Don't leave home without it: the IL- 23 visa to TH-17 cells. Nat Immunol, 10: 236-38.

Cohrs RJ, Gilden DH. 2005. Prevalence and abundance of latently transcribed varicellazoster virus genes 17. Nature Immunol 6: 1133-41.

Coles AJ, Cox, A, Le Page, E. 2006. The window of therapeutic opportunity in multiple sclerosis: Evidence for monoclonal antibody therapy. J Neurol, 253: 98-108.

Colleen MK, Burns BA, and KevinAA. 2006. Does rubella immunity predict méasles immunity? A serosurvey of pregnant women.Infectious Disease Obstetrics and Gynecology. Clinical Study. Hindawi Publishing Corporation. pp. 23.

Colton C.A.; Wilcock, D.M. 2010. Assessing activation states in microglia. CNS Neurol. Disord. Drug Targets, 9: 174-191.

Cooper LZ, Alford CA. 2001. Rubella. In: Remington JS, Klein, JO, eds. Infectious diseases of the fetus and newborninfant. London: W.B. Saunders; 347-87.

Correales J. 2004. Oligoclonal bands and antibody response in multiple sclerosis.In: Focus on Multiple sclerosis Research. Frank Columbus (ed): pp. 37-65.

De Jager, PL \& Hafler, DA. 2007. New therapeutic approaches for multiple sclerosis. Annu Rev Med, 58:417-432.

Del Zoppo, GJ \& Hallenbeck, JM 2000. Advances in the vascularpathophysiology of ischemic stroke. Thromb. Res. 98: 73-81.

Departamento de análisis de datos. 2004. Dirección nacional de estadística y registros médicos. Ministerio de Salud Pública de Cuba, Havana City, Cuba.

Devries HG 2006. Cryptic axonal antigens and axonal loss in multiple sclerosis. Neuroch Res, 29:1999- 2004.

Dutta R, Trapp BD. Pathogenesis of axonal and neuronal damage in multiple sclerosis. Neurology 2007. 68(Supp1 3): S22-S31.

Eikelenboom MJ, Petzold A, Lazeron RHC, Silber E, Sharief M, Thompson EJ; et al. 2003 Neurofilament light chain antibodies are correlated to cerebral atrophy. Neurology, 60: 219-23.

Falip M; Tintore, M; Jardi, R; Duran, I; Link; H \& Montalban, X. 2001.Utilidad clínica de las bandas oligoclonales. Rev Neurol, 32: 1120-24.

Ferreira S, D'Cruz DP, Hughes GRV. 2005. Multiple sclerosis, neuropsychiatric lupus and antiphospholipid syndrome: where do we stand? Rheumatology (Oxford); 44: 434442. 
Fisher LJ \& Gage, F.H. 1993. Grafting in the mammalian central nervous system. Physiol Rev, 73: 583-16.

Forman, ME; Racke, KM \& Raine, SC. 2006. Multiple Sclerosis- the plaque and its pathogenesis. N Eng J Med, 354: 942-55.

Fox RJ, Bethoux F, Goldman MD, Cohen JA. 2006. Multiple sclerosis: advances in understanding, diagnosing, and treating the underlying disease. Cleve Clin J Med, 73: 91-102.

Frederick TJ, Miller SD. 2007. Arresting autoimmunity by blocking beta-arrestin-1. Nat Immunol; 8: 791-792.

Friese, MA \& Fugger, L. 2005. Autoreactive CD8+ T cells in multiple sclerosis: a new target for therapy? Brain, 128: 1747-63.

Frischer J M, Bramow S, Dal-Bianco A, Lucchinetti CF,Rauschka H, Schmidbauer M, Laureen H, Sorensen PS \& Lassmann H. 2009. The relation between inflammation and neurodegeneration in multiple sclerosis brains. Brain, 132; 1175-1189.

Fujinami RS, von Herrath MG, Christen U, Whitton JL. 2006. Molecular mimicry, bystander activation, or viral persistence: infections and autoimmune disease. Clin Microbiol Rev, 19: 80-94.

Gandhi, KS, McKay FC, Schibeci SD, Arthur JW, Heard RN, StewartGJ \& Booth DR. 2008. BAFF is a Biological Response Marker to IFN- $\beta$ Treatment in Multiple Sclerosis. J Inter \& Cytok Res 28: 529-540.

Ghafourifar P, Mousavizadeh K, Parihar MS, et al. Mitochondria in multiple sclerosis. 2008. Front Biosci 13: 3116-3126.

Gorczyca WA, Ejma M, Witkowska D, et al. 2004. Retinal antigens are recognized by antibodies present in sera of patients with multiple sclerosis. Ophthalmic Res; 36: 120-123.

Groom AJ, Smith T, Turski L Xiong ZQ, Qian W, Suzuki K, et al. 2003. Formation of complement membrane attack complex in mammalian cerebral cortex evokes seizures and neurodegeneration. J Neurosci; 23: 955-960.

Haahr S, Hollsberg P. 2006. Multiple sclerosis is linked to Epstein-Barr virus infection. Rev Med Virol, 16: 297-10.

Haukins, BT \& Davis, TP. 2005. The blood-brain barrier/neurovascular unit in health and disease. Pharmacol Rev, 57: 173-85.

Hauser SL, Waubant E, Arnold DL, , et al. 2008. Hermes Trial Group. B-cell depletion with rituximab in relapsing-remitting multiple sclerosis. N Engl J Med; 358: 676-688.

Hemmer, B, Cepok, S, Zhou, D \& Sommer, N. 2004. Multiple sclerosis - a coordinated immune attack across the blood brain barrier. Current Neurovasc Res; 1: 141-50.

Hermitte L, Martin-Moutot N, Boucraut J, et al. 2000. Humoral immunity against glutamic acid decarboxylase and tyrosine phosphatase IA-2. J Clin Immunol; 20: 287-293.

Hickey, WF. 2001. Basic principles of immunological surveillance of the normal central nervous system. Glia, 36: 118-24.

Hillert J. 2006. Multiple sclerosis: postlinkage genetics. Clin Neurol Neurosurg , 108:220-2.

Huizinga R, Linington C, Amor S. 2008. Resistance is futile: antineuronal autoimmunity in multiple sclerosis. Trends Immunol ; 29: 54-60.

Ishizu T, Osoegawa M., Mei F.-J. et al, 2005. Intrathecal activation of the IL-17/IL-8 axis in opticospinal multiple sclerosis. Brain, 128: 988-1002. 
Ishizu, KJ. 2009. Intrathecal activation of the IL-17-IL-8 axis in opticospinal multiple sclerosis. Pharmacol Res, 128: 207-09.

Iwakura Y. \& Ishigame. 2006. The IL-23/IL-17 axis in inflammation. J Clin Invest, 116: 121822.

Jack, C; Jack, A, Wolfgang B \& Tanja K. 2007. Contrasting Potential of Nitric Oxide and Peroxynitrite to Mediate Oligodendrocyte Injury in Multiple Sclerosis. GLIA 55: 926-934.

Jarius S, Eichhorn P, Jacobi C, Wildemann B, Wick M, Voltz R. 2009. The intrathecal, polyspecific antiviral immune response: Specific for MS or a general marker of CNS autoimmunity? J Neurol Sci, 280: 98-100.

Jarius S. 2008. Polyspecific, antiviral immune response distinguishes multiple sclerosis and neuromyelitis optica. Nature Clin Pract Neurol; 4: 524.

Jiang, H \& Chess, L. 2006. Regulation of immune response by T cell. New Engl J Med 354: 1166-76.

Kanda T, Iwasaki T, Yamawaki M, et al. 2000. Anti-GM1 antibody facilitates leakage in an in vitro blood-nerve barrier model. Neurology; 55: 585-87.

Kawanokuchi J, Shimizu K., Nitta A. et al. 2008. Production and functions of IL-17 in microglia. J Neuroimmunol, 194: 54-61.

Kang, J. 1998 Astrocyte-mediated potentiation of inhibitory synaptic transmission. Nat. Neurosci, 1: 683-92.

Keegan M, Kónig F, McClelland R, et al. 2005. Relation between humoral pathological changes in multiple sclerosis and response to therapeutic plasma exchange. Lancet; 366: 579-82.

Kielian T, Esen N and Bearden E. D. 2005. Toll-like receptor 2 (TLR2) is pivotal for recognition of $\mathrm{S}$. aureus peptidoglycan but not intact bacteria by microglia. GLIA, 49: 567-76.

Kira J. 2007. Etiology of multiple sclerosis. In: Multiple Sclerosis for the Practicing Neurologist. Theodore (ed). pp. 1-6, Demos Medical Publishing LLC, Vol 5, New York.

Klawiter, EC \& Cross, AH. 2007. B cells: no longer the nondominant arm of multiple sclerosis. Curr Neurol Neurosci Rep; 7: 231-238.

Komek, BL. 2003. Neuropathology of multiple sclerosis-new concepts. Brain Res Bull, 61: 321-26.

Kraft AD \& Harry GJ. 2011. Features of Microglia and Neuroinflammation Relevant to Environmental Exposure and Neurotoxicity Int. J. Environ. Res. Public Health, 8: 2980-3018

Lambracht-Washington D, O'Connor KC, Cameron EM, et al. 2007. Antigen specificity of clonally expanded and receptor edited cerebrospinal fluid B cells from patients with relapsing remitting MS. J Neuroimmunol; 186: 164-76.

Lampl Y, Boaz M, Gilad R, et al. 2007. Minocycline treatment in acute stroke: an open-label, evaluator-blinded study. Neurology, 69: 1404-10.

Lassmann H, Niedobitek G,Aloisi F, \& Middeldorp JM. 2011. Epstein-Barr virus in the multiple sclerosis brain: a controversial issue-report on a focused workshop held in the Centre for Brain Research of the Medical University of Vienna, Austria. Brain: 134: 2772-86. 
Lee, MA, Palace D, Palace J. 2007. The diagnostic and differential diagnostic in multiple sclerosis.In: Multiple Sclerosis for the Practicing Neurologist Theodore E (ed). New York: Demos Medical Publishing, LLC, Vol 5, p. 33-50.

Levin LI, Munger KL, O'Reilly EJ, Falk KI, Ascherio A. 2010, Primary infection with EpsteinBarr virus and risk of multiple sclerosis. Ann Neurol; 67: 824-30.

Lim, ET, Sellebjerg, F, Jensen, CV, Altmann, DR, Grant, D \& Keir, G. 2005 .Acute axonal damage predicts clinical outcome in patients with multiple sclerosis. Mult Scler ,11: 532-6.

Lindberg RL, Achtnichts L, Hoffmann F, et al. 2008. Natalizumab alters transcriptional expression profiles of blood cell subpopulations of multiple sclerosis patients. J Neuroimmunol; 194: 153-64.

Lipton SA, Rosenberg PA. 1994. Excitatory amino acids as a final common pathway for neurologic disorders. N Engl J Med; 330: 613-22.

Lisak, PR. 2007.Neurodegeneration in multiple sclerosis.Defining the problem. Neurology 2007; 68: S5-S12.

Loeb JA. 2007. Neuroprotection and repair by neurotrophic and gliotrophic factors in multiple sclerosis. Neurology; 68(Suppl 3): 38-54.

Lovato L, Willis SN, Rodig SJ, Caron T, Almendinger SE, Howell OW, et al. 2011. Related B cell clones populate the meninges and parenchyma of patients with multiple sclerosis. Brain; 134: 534-41.

Lu F, Kalman B. 1999. Autoreactive IgG to intracellular proteins in sera of MS patients. J Neuroimmunol; 99:72-81.

Lu J, Murakami M, Verma SC, Cai Q, Haldar S, Kaul R, et al. 2011. Epstein-Barr virus nuclear antigen 1 (EBNA1) confers resistance to apoptosis in EBV-positive Blymphoma cells through upregulation of survivin. Virology; 410: 64-75.

Lucchinetti, C, Brück W, Scheithauer B, Rodriguez M Lassman H. 2000, Heterogeneity of multiple sclerosis lesions: implications for the pathogenesis of demyelination. Ann Neurol, 47: 707-17.

Luchinetti CF. 2007. Advances in the neuropathology of multiple sclerosis: evolving pathogenesis insight. Continuum Lifelong Learning. Neurology 13: 86-116.

Lutterotti A, Berger T, Reindl M. 2007. Biological markers for multiple sclerosis. Curr Med Chem; 14:1956-65.

Maes M, Kubera M., and Leunis JC. 2008. The gut-brain barrier in major depression: intestinal mucosal dysfunction with an increased translocation of LPS from gram negative enterobacteria (leaky gut) plays a role in the inflammatory pathophysiology of depression. Neuroendocrinol Letters, 29: 117-24.

Maes M, Coucke F, and Leunis JC. 2007. Normalization of the increased translocation of endotoxin from gram negative enterobacteria (leaky gut) is accompanied by a remission of chronic fatigue syndrome. Neuroendocrinol Letters, 28: 739-44.

Maghzi AH, Marta M, Bosca I, Etemadifar M, Dobson R, Maggiore C, et al. 2010. Viral pathophysiology of multiple sclerosis: a role for Epstein-Barr virus infection? Pathophysiology; 18: 13-20.

Magliozzi R, Howell OW, Reeves C, Roncaroli F, Nicholas R, Serafini B, et al. 2010. A gradient of neuronal loss and meningeal inflammation in multiple sclerosis. Ann Neurol; 68: 477-93. 
Maier O, Baron W, Hoekstra D. 2007. Reduced raft-association of NF155 in active MS-lesions is accompanied by the disruption of the paranodal junction. Glia; 55: 885-95.

Marconi S, Acler M, Lovato L, et al. 2006. Anti-GD2-like IgM autoreactivity in multiple sclerosis patients. Mult Scler; 12: 302-08.

Martinez, A; Mas, A; de las Heras, V; Arroyo, R; Fernandez-Arquero, M; de la Concha, EG et al. 2005. Early B-cell Factor gene association with multiple sclerosis in the Spanish population. BMC Neurol, 5: 19-22.

Martinez-Yélamos, S, Ballabriga, J, Martinez-Yélamos, A, Hernandez, JJ \& Arbizu, T. 1998. Evolución y pronóstico de la esclerosis múltiple. Medicine; 7: 4333-37.

Mathey EK, Derfuss T, Storch MK, et al. 2007. Neurofascin as a novel target for autoantibody-mediated axonal injury. J Exp Med; 204: 2363-72.

Matute C, Domercq M, Sanchez-Gomez MV. 2006. Glutamate-mediated glial injury: mechanisms and clinical importance. Glia; 53: 212-24.

McCoy, L; Tsunoda, I \& Fuginami, RS. 2006. Multiple sclerosis and virus induced immune responses: autoimmunity can be primed by molecular mimicry and augmented by bystander activation. Autoimmunity, 39: 9-19.

McDonald, W, Compston, A, Edan, G, Hangtung, H, Lublin, F, McFarland H et al. 2001. Recommended diagnostic criteria for multiple sclerosis. Ann Neurol , 50: 121-27.

McGeachy M. J., Chen Y, Tato C.M et al. 2009. The interleukin 23 receptor is essential for the terminal differentiation of interleukin 17-producing effector T helper cells in vivo. Nat Immunol, 10: 314-24.

Meinl E, Krumbholz M, Derfuss T, Junker A,Hohlfeld R. 2008. Comparmentalization of inflammaion in the CNS:A major mechanism driving progressive multiple sclerosis. J Neurol Sci; 274: 42-44.

Mi S, Miller RH, Tang W, Lee X, Hu B, Wu W, Zhang Y, Shields CB, Zhang Y, Miklasz S, Shea D, Mason J, Franklin RJ, Ji B, Shao Z, Chédotal A, Bernard F, Roulois A, Xu J, Jung V, Pepinsky B. 2009. Promotion of central nervous system remyelination by induced differentiation of oligodendrocyte precursor cells. Ann Neurol; 65: 304-15.

Miron VE, Jung CG, Kim HJ, Kennedy TE, Soliven B \&. Antel JP. 2008. FTY720 Modulates Human. Oligodendrocyte Progenitor Process Extension and Survival Ann Neurol; 63: 61-71.

Mirsattari, SM, Johnston, J, McKenna R, et al. 2001. Aborigenals with multiple sclerosis HLA types and proedominance of neuromyelitis óptica. Neurology, 56: 317-23.

Monteleone G., Pallone F, \& MacDonald T.T. 2008. Interleukin- 21: a critical regulator of the balance between effector and regulatory T-cell responses. Trends Immunol, 29: 290-94.

Mosmann T. R.; H. Cherwinski, M.W.; Bond, M.A.; Giedlin, \& Coffman R.L. 1986. Two types of murine helper T cell clone. I. Definition according to profiles of lymphokine activities and secreted proteins. J Immunol, 136: 2348-57.

Nag, S. 2003. Pathophysiology of blood brain barrier breakdown. Methods Mol Med, 89: 97111.

Nathanson, JA \& Chun, LYL. 1990. Possible role of the choroid plexus in immunological communication between the brain and periphery. BB Johansson, Ch Owman, $\mathrm{H}$ Widner (Eds). In. Pathophysiology of the blood brain barrier, Elsevier Science Publisher, pp. 501 505.New York. 
Nathanson, JA, Chun, LYL. 1990a. Immunological function of the blood- cerebrospinal fluid barrier. Proc Natl Acad Sci. USA, 86: 1684-88.

Ness, JM; Chabas, D; Sadovnick, AD; Pohl, D; Banwell, B \& Weinstock-Guttman, B. 2007. Clinical features of children and adolescents with multiple sclerosis. Neurology, 68; 37-45.

Neumann, H, Medana, IM, Bawer, J \& Lassmann, H. 2002. Cytotoxic T lymphocyte in autoimmune and degenerative CNS diseases. Trends Neurosci, 25: 313-19.

Neutwelt, E, Abbott, NJ , Abrey, L, Banks, W A, Blakley, B, Davis, T, et al. 2008. Strategies to advance translational research into brain barriers. Lancet Neurol; 7: 84-96.

$\mathrm{O}^{\prime}$ Connor KC, Cameron EM, et al. 2007. Antigen specificity of clonally expanded and receptor edited cerebrospinal fluid B cells from patients with relapsing remitting MS. J Neuroimmunol; 186: 164-76.

Owens GP, Burgoon MP, Anthony J, et al. 2001. The immunoglobulin G heavy chain repertoire in multiple sclerosis plaques is distinct from the heavy chain repertoire in peripheral blood lymphocytes. Clin Immunol; 98: 258-263.

Pender MP. 2011. The essential role of Epstein-Barr Virus in the pathogenesisof multiple sclerosis. Neuroscientist, 17: 351-67.

Perry, V H \& Gordon, S. 1997. Microglias and macrophages. In: Immunology of the nervous system, R W Keane and WE Hickey (eds), pp (155-172) Oxford University Press,New York.

Petty, MA \& Lo, HE. 2002. Junctional complexes of the blood-brain barrier: permeability changes in neuroinflammation. Prog Neurobiol, 68: 311-23.

Pittock, SJ, Mayr, WT, McClelland RL. 2004. Change in MS-related disability in a population- based cohort: a 10- year follow-up study. Neurology; 62: 51-59.

Porras-Betancourt, M; Nuñez-Orozco, L; Plascencia-Alvarez, NI; Quiñones-Aguilar, S \& Sauri-Suarez, S. 2007. Esclerosis Multiple. Rev Mex Neurosc; 8: 57-66.

Prat A, Antel J. 2005. Pathogenesis of multiple sclerosis.Curr Opin Neurol , 18: 225-30.

Rauer, S; Euler, B; Reindl,M \& Berger TH. 2006. Antimyelin antibodies and the risk of relapse in patients with a primary demyelinating event. J Neurol Neurosurg Psychiatry, 77: 739-42.

Redzic, ZB, Preston, JE, Duncan, JA, Chdobski, A \& Szmydynger Chdobsk, J. 2005. The choroid plexus- cerebrospinal fluid system from development to ageing. Curr Top Dev Biol, 71: 1-52.

Reese, TS \& Karnowosky, MJ 1967. Fine structural localization of a blood-brain barrier to exogenous peroxidase. J Cell Biol 34: 207-17.

Reiber H, Ungefehr ST, Jacobi CHR. 1998. The intrathecal, polyspecific and oligoclonal immune response in multiple sclerosis. Mult Scler; 4: 111-17.

Rivest S. 2009. Regulation of innate immune responses in the brain. Nat. Rev. Immunol, 9: 429-39.

Robinson-Agramonte MA. 2010. Asimilación del método de focalización isoeléctrica en agarosa y aplicación del ELISA al estudio de la respuesta de anticuerpos en el sistema nervioso central de personas con esclerosis múltiple. Revista CENIC Ciencias Biológicas, 21: 206-07.

Robinson-Agramonte M, Reiber H, Cabrera-Gomez JA, Galvizu R. 2007. Intrathecal polyspecific immune response to neurotropic viruses inmultiple sclerosis: a comparative report from Cuban patients. Acta Neurol Scand, 115: 312-18. 
Robinson-Agramonte M, Reiber H, Dorta-Contreras AJ,Herna'ndez-Diaz E. 2001. Respuesta inmune intratecal oligoclonaly poliespecı́fica en la esclerosis múltiple. Rev Neurol; 33: 809-11.

Rock R. B, Gekker G, Hu S et al. 2004. Role ofmicroglia in central nervous system infections. Clinical Microbiology Reviews, 17: 942-64.

Rose, WJ \& Carlson, GN. 2007. Pathogenesis of multiple sclerosis. Continuum Lifelong Learning Neurol , 13: 35-62.

Roussel V, Yi F, Jauberteau MO, et al. 2000. Prevalence and clinical significance of antiphospholipid antibodies in multiple sclerosis: a study of 89 patients. J Autoimmun; 14: 259-65.

Sarchielli P, Greco L, Floridi A, et al. 2003. Excitatory amino acids and multiple sclerosis: evidence from cerebrospinal fluid. Arch Neurol; 60: 1082-88.

Semra YK, Seidi OA, Sharief MK. 2002. Heightened intrathecal release of axonal cytoskeletal proteins in multiple sclerosis is associated with progressive disease and clinical disability. J Neuroimmunol, 122: 132-39.

Serafini B, Severa M, Columba-Cabezas S, Rosicarelli B, Veroni C, Chiappetta G, et al. 2010. Epstein-Barr virus latent infection and BAFF expression in B-cells in the multiple sclerosis brain: implications for viral persistence and intrathecal B-cell activation. J Neuropath Exp Neurol; 69: 677-93.

Seyfert, S \& Faultish, A. 2003. Is the blood-CSF barrier alterated in disease? Acta Neurol Scand, 108: 252-56.

Shi Y, Feng Y, Kang J, et al. 2007. Critical regulation of CD4+ T cell survival and autoimmunity by beta-arrestin-1. Nat Immunol; 8: 817-24.

Silber, E; Semra, YK; Gregson, NA \& Sharief MK. 2002. Patients with progressive multiple sclerosis have elevated antibodies to neurofilament subunit. Neurology 58: 1372-78.

Smith T, Groom A, Zhu B, et al. 2000. Autoimmune encephalomyelitis ameliorated byAMPA antagonists. Nat Med; 6: 62-66.

Sobel, RA. 1998. The extracellular matrix in multiple sclerosis lesions.J Neuropathol Exp Neurol, 57: 205-17

Sospedra, M \&. Martin, R. 2009. MRI criteria in MS patients with negative and positive oligoclonal bands: equal fulfillment of Barkhof's criteria but different lesion patterns. J Neurol, 256: 1121-25.

Steinman L. 2007. A brief history of TH17, the first major revision in the TH1/TH2 hypothesis of T cell-mediated tissue damage. Nature Medicine, 13: 139-45.

Sternberg Z, Chadha K, Lieberman A et al. 2008. Quercetin and interferon- $\beta$ modulate immune response(s) in peripheral blood mononuclear cells isolated from multiple sclerosis patients. Journal of Neuroimmunology, 205: 142-47.

Stockinger \& Veldhoen M. 2007. Differentiation and function of Th17 T cells. Curr Op Immunol,19: 281-86.

Chung Y. \& Dong C. 2009. Don't leave home without it: the IL- 23 visa to TH-17 cells. Nat Immunol, 10: 236-38.

Stromnes I. M., Cerretti L.M, Liggitt D., Harris R.A. \& Goverman J. M. 2008. Differential regulation of central nervous system autoimmunity by TH1 and TH17 cells. Nature Medicine, 14: 337-42.

Stys PK, Lipton SA. 2007. White matter NMDA receptors: an unexpected new therapeutic target? Trends Pharmacol Sci; 28: 561-66. 
Taplin CE, Barker JM. 2008. Autoantibodies in type 1 diabetes. Autoimmunity; 41: 11-18.

Tester A.M., Cox J. H., Connor A. R. et al, 2007. LPS responsiveness and neutrophil chemotaxis in vivo require PMN MMP-8 activity. PLoS ONE, 2: article e312.

Theiss C, Napirei M, Meller K. 2005. Impairment of anterograde and retrograde neurofilament transport after anti-kinesin and anti-dynein antibody microinjection in chicken dorsal root ganglia. Eur J Cell Biol 84: 29-43.

Torkildsen, O; Vedeler, CA; Nyland, HI; Myhr KM. 2006. Fc $\gamma$ R and multiple sclerosis: an overview. Acta Neurol Scand ,113: 61-63.

Vercellino M, Merola A, Piacentino C, et al. 2007. Altered glutamate reuptake in relapsingremitting and secondary progressive multiple sclerosis cortex: correlation with microglia infiltration, demyelination, and neuronal and synaptic damage. J Neuropathol Exp Neurol; 66: 732-39.

Villar, LM; Sádaba,MC;Roldán, E; Masjuan, J; González, P; Villarrubia, N; et al. 2005. Intrathecal synthesis of oligoclonal IgM against myelin lipids predicts an aggressive disease course in MS. J Clin Invest,115 :187-90.

Vojdani A \& Lambert J. 2011a The Role of Th17 inNeuroimmuneDisorders: Target for CAM Therapy. Part II Hindawi Publishing Corporation Evidence-Based Complementary and Alternative Medicine Volume 1-7.

Vojdani A \& Lambert; J. 2011.The Role of Th17 inNeuroimmuneDisorders: Target for CAM Therapy. Part I Hindawi Publishing Corporation Evidence-Based Complementary and Alternative Medicine Volume 1-8.

Vyshkina T \& Kalman B. 2008. Autoantibodies and neurodegeneration in multiple sclerosis. Lab Invest, 1-12.

Wallstrom E, Diener P, Ljungdahl A, et al. 1996. Memantine abrogates neurological deficits, but not CNS inflammation, in Lewis rat experimental autoimmune encephalomyelitis. J Neurol Sci; 137: 89-96.

Weinstock-Guttman B; Ramanathan M; Lincoff N; Napoli SQ; Sharma J; et al. 2006. Study of Mitoxantrone for the Treatment of Recurrent Neuromyelitis Optica Devic Disease. Arch Neurol, 63: 957-63.

Wilson C. B, Rowell E. \& Sekimata M. 2009. Epigenetic control of T-helper-cell differentiation. Nat Rev Immunol, 9: 91-105.

Winer JB. 2001. Guillain Barre syndrome. Mol Pathol; 54: 381-85.

Wingerchuck, D \& Kantarci O. 2006. Epidemiology and natural history of multiple sclerosis: new insights. Curr Opin Neurol, 19: 248-54.

Zaffaroni M. 2003. Biological indicators of the neurodegenerative phase of multiple sclerosis. Neurol Sci; 24 (Suppl 5): S279-S282.

Zheng et al. 2007. Interleukin-22, a TH17 cytokine, mediates IL-23-induced dermal inflammation and acanthosis. Nature, 445 (7128): 648-51. 


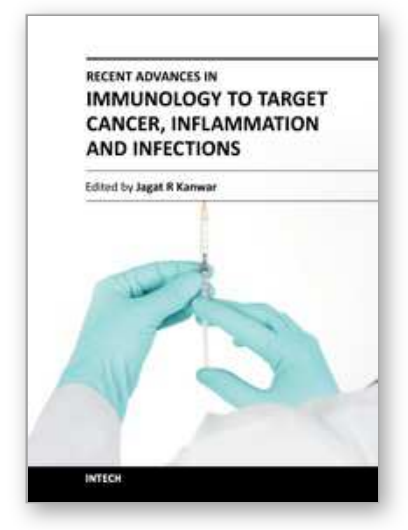

\author{
Recent Advances in Immunology to Target Cancer, Inflammation \\ and Infections \\ Edited by Dr. Jagat Kanwar
}

ISBN 978-953-51-0592-3

Hard cover, 520 pages

Publisher InTech

Published online 09, May, 2012

Published in print edition May, 2012

Immunology is the branch of biomedical sciences to study of the immune system physiology both in healthy and diseased states. Some aspects of autoimmunity draws our attention to the fact that it is not always associated with pathology. For instance, autoimmune reactions are highly useful in clearing off the excess, unwanted or aged tissues from the body. Also, generation of autoimmunity occurs after the exposure to the non-self antigen that is structurally similar to the self, aided by the stimulatory molecules like the cytokines. Thus, a narrow margin differentiates immunity from auto-immunity as already discussed. Hence, finding answers for how the physiologic immunity turns to pathologic autoimmunity always remains a question of intense interest. However, this margin could be cut down only if the physiology of the immune system is better understood. The individual chapters included in this book will cover all the possible aspects of immunology and pathologies associated with it. The authors have taken strenuous effort in elaborating the concepts that are lucid and will be of reader's interest.

\title{
How to reference
}

In order to correctly reference this scholarly work, feel free to copy and paste the following:

Maria de los Angeles Robinson-Agramonte, Alina González-Quevedo and Carlos Alberto Goncalves (2012). Glial and Axonal Pathology in Multiple Sclerosis, Recent Advances in Immunology to Target Cancer, Inflammation and Infections, Dr. Jagat Kanwar (Ed.), ISBN: 978-953-51-0592-3, InTech, Available from: http://www.intechopen.com/books/recent-advances-in-immunology-to-target-cancer-inflammation-andinfections/glia-and-axonal-pathology-in-multiple-sclerosis

\section{INTECH}

open science | open minds

\section{InTech Europe}

University Campus STeP Ri

Slavka Krautzeka 83/A

51000 Rijeka, Croatia

Phone: +385 (51) 770447

Fax: +385 (51) 686166

www.intechopen.com

\section{InTech China}

Unit 405, Office Block, Hotel Equatorial Shanghai

No.65, Yan An Road (West), Shanghai, 200040, China 中国上海市延安西路65号上海国际贵都大饭店办公楼405单元

Phone: +86-21-62489820

Fax: +86-21-62489821 
(C) 2012 The Author(s). Licensee IntechOpen. This is an open access article distributed under the terms of the Creative Commons Attribution 3.0 License, which permits unrestricted use, distribution, and reproduction in any medium, provided the original work is properly cited. 